\title{
¿Scale Analysis of Moist Thermodynamics in a Simple Model and the Relationship between Moisture Modes and Gravity Waves
}

\author{
ÁNGEL F. AdAMES \\ Department of Climate and Space Science and Engineering, University of Michigan, Ann Arbor, Michigan \\ DAEHYUN KIM \\ Department of Atmospheric Sciences, University Of Washington, Seattle, Washington \\ SPENCER K. CLARK \\ Program in Atmospheric and Oceanic Sciences, Princeton University, Princeton, New Jersey \\ YI MING \\ NOAA/Geophysical Fluid Dynamics Laboratory, Princeton, New Jersey \\ KUNIAKI INOUE \\ NASA Goddard Institute for Space Studies, and Lamont-Doherty Earth Observatory, \\ Columbia University, New York, New York
}

(Manuscript received 6 May 2019, in final form 12 August 2019)

\begin{abstract}
Observations and theory of convectively coupled equatorial waves suggest that they can be categorized into two distinct groups. Moisture modes are waves whose thermodynamics are governed by moisture fluctuations. The thermodynamics of the gravity wave group, on the other hand, are rooted in buoyancy (temperature) fluctuations. On the basis of scale analysis, it is found that a simple nondimensional parameter - akin to the Rossby number-can explain the processes that lead to the existence of these two groups. This parameter, defined as $N_{\text {mode }}$, indicates that moisture modes arise when anomalous convection lasts sufficiently long so that dry gravity waves eliminate the temperature anomalies in the convective region, satisfying weak temperature gradient (WTG) balance. This process causes moisture anomalies to dominate the distribution of moist enthalpy (or moist static energy), and hence the evolution of the wave. Conversely, convectively coupled gravity waves arise when anomalous convection eliminates the moisture anomalies more rapidly than dry gravity waves can adjust the troposphere toward WTG balance, causing temperature to govern the moist enthalpy distribution and evolution. Spectral analysis of reanalysis data indicates that slowly propagating waves $\left(c_{p} \sim 3 \mathrm{~m} \mathrm{~s}^{-1}\right)$ are likely to be moisture modes while fast waves $\left(c_{p} \sim 30 \mathrm{~m} \mathrm{~s}^{-1}\right)$ exhibit gravity wave behavior, with "mixed moisture-gravity" waves existing in between. While these findings are obtained from a highly idealized framework, it is hypothesized that they can be extended to understand simulations of convectively coupled waves in GCMs and the thermodynamics of more complex phenomena.
\end{abstract}

\section{Introduction}

Since the beginning of the satellite era, observations of the horizontal distribution of tropical cumulus clouds

Denotes content that is immediately available upon publication as open access.

Corresponding author: Ángel F. Adames, afadames@umich.edu and their time evolution have shown that convective clouds organize into a wide variety of spatial and temporal scales (Chang 1970; Yanai and Murakami 1970b,a; Wallace and Chang 1972; Reed and Recker 1971). Examples of organized convection include mesoscale convective systems (Houze 2004), convectively coupled equatorial waves (Kiladis et al. 2009), and the MaddenJulian oscillation (MJO) (Madden and Julian 1971, 1972). Understanding the mechanisms through which 
convective clouds organize at different scales and propagate with respect to the mean flow has been a challenging task due to the complex interactions among convection, wind, moisture, and radiation in the tropics, where in situ observations are sparse.

Before satellite-based observations of tropical convection were made, Matsuno (1966) obtained a set of wave solutions to a system of "dry" shallow-water equations on an equatorial beta plane linearized with respect to a resting basic state. The waves identified by Matsuno include the equatorial Rossby wave, the equatorial Kelvin wave, the mixed Rossby-gravity wave, and the eastwardand westward-propagating inertio-gravity waves.

Spectral analysis of satellite brightness temperature data (Takayabu 1994; Wheeler and Kiladis 1999; Wheeler et al. 2000) showed that a majority of the peaks in the spectral power over the wavenumber-frequency space follow the dispersion curves of the waves in the shallowwater system, albeit with a smaller "equivalent depth" than that predicted by purely dry theory. Numerous studies have accounted for this smaller depth in terms of latent heating that is incorporated diagnostically by way of the large-scale vertical velocity. Prescribing convection this way simply slows down the waves by lowering the effective static stability without affecting the wave characteristics in any other ways [see Eq. (19) of Kiladis et al. (2009)]. While this description of convection is simple, the framework does not lead to solutions where a fastest growing mode can be identified. Therefore, it is incomplete since it does not explain the observed horizontal scale of the waves. This shortcoming has led many authors to focus on moist thermodynamics as a mechanism of convective coupling and instability in these waves as well as a means of describing the scale preference (Mapes 2000; Majda et al. 2004; Raymond and Fuchs 2007; Kuang 2008).

Recently, there has been considerable effort to reveal the role of moisture as a dynamically active variable in the tropical atmosphere, especially after a tight coupling between tropical convection and environmental moisture was reported from observations (Sobel 2002; Bretherton et al. 2004; Holloway and Neelin 2009; Rushley et al. 2018). Including moisture as a prognostic variable in simple models of the tropical atmosphere yields new modes that do not exist in a dry system (Fuchs and Raymond 2002, 2005, 2017; Sugiyama 2009; Raymond and Fuchs 2009; Sobel and Maloney 2012, 2013; Adames and Kim 2016), which are collectively called "moisture modes." The existence of moisture modes suggests that the dry assumption used in the Matsuno model might not describe all of the convectively coupled waves that exist in the tropical atmosphere.

Observational and modeling studies indicate that moisture modes may exist, and the MJO may be a physical manifestation of one (Andersen and Kuang 2012; Pritchard and Bretherton 2014; Sobel et al. 2014; Benedict et al. 2014; Wolding et al. 2016; Jiang et al. 2018). The MJO's spectral signature exhibits a high coherence between water vapor and precipitation [see Figs. 1 and 4 in Yasunaga and Mapes (2012)]. Furthermore, the central role that water vapor plays in the convective organization of the MJO has been documented by numerous studies (Grabowski and Moncrieff 2004; Del Genio et al. 2012; Andersen and Kuang 2012; Shi et al. 2018).

Recent theoretical models indicate that moisture may also play a central role in the thermodynamics of equatorial Rossby waves and tropical depression (TD)-like disturbances such as some easterly waves and monsoon low pressure systems (Fuchs-Stone et al. 2019; Gonzalez and Jiang 2019; Rydbeck and Maloney 2015; Adames and Ming 2018). These tropical motion systems are also characterized by a balanced wind field and slow propagation (Raymond et al. 2015). Along with the MJO, equatorial Rossby waves and TD-like disturbances can be considered to comprise the moisture mode group of tropical motion systems.

Beside the moisture mode group, another group of tropical motion systems exists. These exhibit fast propagation speeds of $\sim 15 \mathrm{~m} \mathrm{~s}^{-1}$ or higher. Temperature (buoyancy) fluctuations are considered central to their thermodynamics (Mapes 2000; Mapes et al. 2006; Khouider and Majda 2006; Raymond and Fuchs 2009; Raymond et al. 2015; Herman et al. 2016; Khouider 2019). This category includes Kelvin waves, mixed Rossby-gravity waves and inertio-gravity waves. Collectively, these waves will be referred to as the gravity wave group. This categorical view of convectively coupled tropical motion systems is shown schematically in Fig. 1a.

While the separation of waves into two categories may provide a useful framework to analyze these waves, several studies indicate that the boundary between the two groups is not as distinct as previously thought. For example, Roundy (2012a) found that the horizontal and vertical structure of convectively coupled Kelvin waves becomes more similar to that of the MJO as its equivalent depth becomes smaller. Another study by Roundy (2012b) showed that the spectral signatures of Kelvin waves and the MJO are continuous over regions of mean westerly winds. These two studies indicate that the distinction between the MJO and Kelvin waves may not be clear. A separate study by Sobel and Kim (2012) analyzed the MJO's circulation features as they decouple from convection in the equatorial central Pacific. They found that a transition between the slowly propagating MJO convection and the faster planetary-scale Kelvin wave may exist during this decoupling process. A recent study by Powell (2017) indicates that MJO convection 
(a) Category-based view

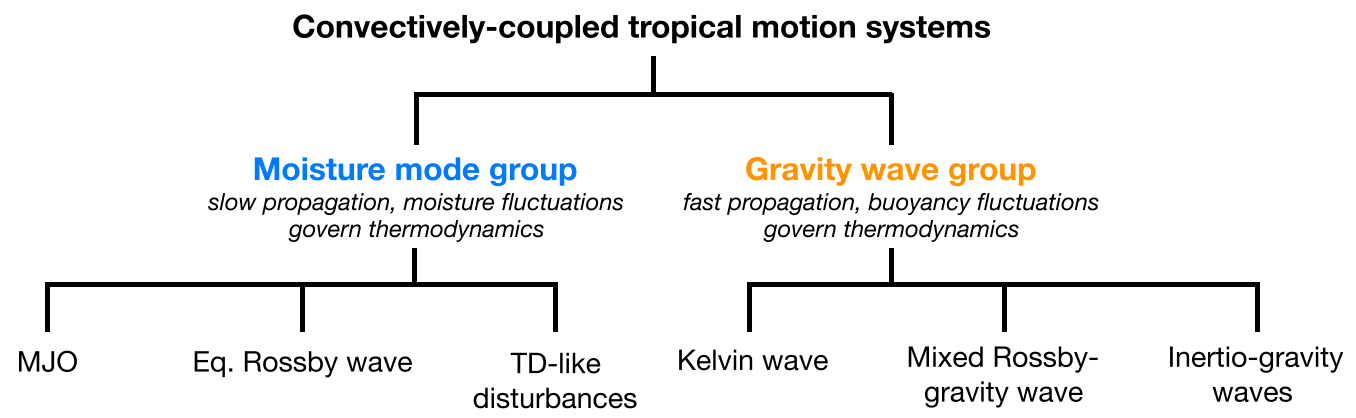

(b) Continuum view

\begin{tabular}{|ccccc|} 
Moisture mode group & \multicolumn{2}{c}{ Mixed moisture-gravity waves } & \multicolumn{2}{c|}{ Gravity wave group } \\
\hline MJO & $\begin{array}{c}\text { TD-like } \\
\text { Eq. Rossby wave }\end{array}$ & Kelvin wave & $\begin{array}{c}\text { Inertio-gravity waves } \\
\text { MRG wave }\end{array}$ \\
\hline 0 & $10^{-1}$ & & $10^{0}$ \\
$N_{\text {mode }}$ & & $10^{1}$ & $\rightarrow \infty$ \\
\hline
\end{tabular}

FIG. 1. Two ways in which convectively coupled tropical motion systems can be organized. (a) In a category-based view, the thermodynamics of tropical motion systems correspond to either the moisture mode group or the gravity wave group. (b) In a continuum-based view, the two categories described in (a) form the ends of a spectrum. All tropical motion systems fall somewhere in this spectrum. The nondimensional scale described in this study, that is, $N_{\text {mode }}$, specifies where in the spectrum a phenomenon may be located.

over the Indo-Pacific warm pool can be interpreted as a moisture mode. Away from the warm pool, the propagation of convection occurs at a phase speed that is consistent with a Kelvin wave that is weakly coupled to convection. During the transition period that was described by Sobel and Kim (2012), Powell (2017) suggests that the MJO may exhibit characteristics that are a blend of a moisture mode and a Kelvin wave.

In this study, we will show that the moist enthalpy budget offers a unified view of the two groups of tropical motion systems. A nondimensional scale defined as $N_{\text {mode }}$ describes the conditions that lead to moisture mode behavior versus gravity wave behavior. Moisture mode behavior predominates when moisture is the dominant contributor to moist enthalpy while gravity wave behavior is dominant when temperature governs the distribution of moist enthalpy. The two groups are bridged by an intermediate "mixed moisture-gravity" wave group: waves whose thermodynamics exhibit properties of both moisture modes and gravity waves. Our results indicate that moisture modes and gravity waves are the bookends of a thermodynamic spectrum of waves, as depicted in Fig. 1b. While the framework presented here may not adequately describe the structure and instability of observed waves, it does offer a framework in which their thermodynamics can be qualitatively understood.
This study is structured as follows. The following section discusses the theoretical framework including the basic equations, scale analysis and linear wave solutions. Section 3 discusses the conditions that lead to gravity wave and moisture mode behavior in observations and reanalysis data. Our results are synthesized and discussed in further detail in section 4 .

\section{Theory}

\section{a. Basic equations}

We will perform our analysis on a set of shallow-water basic equations that correspond to a convectively coupled wave with no meridional wind $(v=0)$. The coupling with convection is dictated through a prognostic moisture equation under moist convective adjustment (Betts and Miller 1986; Betts 1986). This is a similar framework to that analyzed by Neelin and Yu (1994), Fuchs and Raymond (2002), and Fuchs and Raymond (2017), who analyzed $v=0$ moist waves under moist convective adjustment. This analysis has numerous limitations, since observed Kelvin waves exhibit significant tilts in their fields (Straub and Kiladis 2003; Kiladis et al. 2009; Herman et al. 2016) and other waves, such as the MJO, have a meridional wind field that play an important role 
in their dynamics (Kim et al. 2014; Adames et al. 2016). However, we posit that the scaling obtained from this system of equations is also valid for waves that exhibit more complex features, including the Kelvin wave and the MJO, as shown in appendixes B-D. Our choice of focusing our discussion on the $v=0$ wave stems from its simple wave solutions, which will be used to support the scale analysis.

The main variables and definitions used in this section are shown in Table 1 . We begin by separating all field variables into time-mean (denoted by an overbar) and perturbation (denoted by a prime) components, for example,

$$
\Phi=\bar{\Phi}+\Phi^{\prime},
$$

where $\Phi$ is the geopotential. The mean state will be assumed to be precipitating, in approximate hydrostatic and weak temperature gradient (WTG) (Sobel and Bretherton 2000; Sobel et al. 2001) balances and characterized by weak uniform easterlies. This is the same scaling used in other previous studies (Neelin et al. 1987; Emanuel 1987; Adames and Kim 2016; Fuchs and Raymond 2017). The perturbations are vertically truncated using basis functions (Neelin and Zeng 2000; Adames and Kim 2016; Adames and Ming 2018), for example,

$$
\Phi^{\prime}(x, y, p, t)=\phi^{\prime}(x, y, t) \Lambda(p),
$$

where the uppercase $\Phi^{\prime}$ denotes the four-dimensional geopotential, the lowercase $\phi^{\prime}$ denotes the vertically truncated geopotential, and $\Lambda$ is the structure function for a first baroclinic mode in the wind and geopotential field. Further description of the vertical structure functions is found in appendix A.

The basic equations are vertically integrated in order to explicitly represent the anomalies in moisture and heat sources in terms of an anomalous precipitation rate $P^{\prime}$. The vertically integrated specific humidity $q$ is defined as

$$
\langle q\rangle=\frac{1}{g} \int_{p_{t}}^{p_{s}} q d p,
$$

where $g=9.8 \mathrm{~m} \mathrm{~s}^{-2}$ is the gravitational acceleration, and $p_{t}=100 \mathrm{hPa}$ and $p_{s}=1000 \mathrm{hPa}$ are the tropopause and surface pressures, respectively. Other variables are vertically integrated in the same way. The vertically truncated and integrated basic equations can be treated as shallow-water equations.

The column-integrated water vapor anomalies are related to the precipitation anomalies through the use of a simplified Betts-Miller scheme (Betts and Miller 1986; Betts 1986; Frierson 2007)
TABLE 1. Mean state variables used in this study. In the units column a long dash indicates nondimensional.

\begin{tabular}{lcc}
\hline \multicolumn{1}{c}{ Variable } & Symbol & Units \\
\hline Specific heat of dry air at constant pressure & $C_{p}$ & $\mathrm{~J} \mathrm{~kg}^{-1} \mathrm{~K}^{-1}$ \\
Latent energy of vaporization & $L_{v}$ & $\mathrm{~J} \mathrm{~kg}^{-1}$ \\
Column moisture anomaly & $\left\langle q^{\prime}\right\rangle$ & $\mathrm{kg} \mathrm{m}^{-2}$ \\
Column moist enthalpy anomaly & $h^{\prime}$ & $\mathrm{J} \mathrm{m}^{-2}$ \\
Truncated horizontal wind anomaly & $\mathbf{v}^{\prime}$ & $\mathrm{m} \mathrm{s}^{-1}$ \\
Truncated geopotential anomaly & $\phi^{\prime}$ & $\mathrm{m}^{2} \mathrm{~s}^{-2}$ \\
Truncated temperature anomaly & $\tau^{\prime}$ & $\mathrm{K}$ \\
Convective moisture adjustment time scale & $\tau_{c}$ & $\mathrm{~s}$ \\
Gravity wave adjustment time scale & $\tau_{g}$ & $\mathrm{~s}$ \\
Free gravity wave phase speed & $c$ & $\mathrm{~m} \mathrm{~s}^{-1}$ \\
Mean gross dry stability & $\bar{M}_{s}$ & $\mathrm{~J} \mathrm{~m}^{-2}$ \\
Mean gross moisture stratification & $\bar{M}_{q}$ & $\mathrm{~J} \mathrm{~m}^{-2}$ \\
Normalized gross moist stability & $\tilde{M}_{\mathrm{eff}}$ & - \\
Effective gross moist stability & $A_{K}$ & - \\
Moisture advection parameter & $\delta \bar{q}_{u}$ & $\mathrm{~J} \mathrm{~m}^{-1}$ \\
Moisture tendency associated with $\mathrm{u}^{\prime}$ & $R_{e}$ & $\mathrm{~km}^{-3}$ \\
Equatorial Rossby radius of deformation & $\Omega$ & $\mathrm{Pa}^{\prime}$ \\
Vertical velocity basis function & $\Lambda$ & - \\
Wind/geopotential basis function & $a$ & - \\
Temperature basis function & $k$ & $\mathrm{~m}^{-1}$ \\
Zonal wavenumber & $\omega$ & $\mathrm{s}^{-1}$ \\
Wave frequency & & \\
\hline
\end{tabular}

$$
P^{\prime}=\left\langle q^{\prime}\right\rangle / \tau_{c}
$$

where $\tau_{c}$ is the convective moisture adjustment time scale, a measure of the sensitivity of precipitation to changes in the column-integrated water vapor. It can also be interpreted as the time scale in which anomalous precipitation relaxes water vapor toward a climatologicalmean value. Estimates of $\tau_{c}$ based on the observed relationship between water vapor and precipitation indicate that $\tau_{c}$ varies from 6 to $24 \mathrm{~h}$ over the climatologically rainy regions of the tropics (Jiang et al. 2016; Adames 2017; Rushley et al. 2018). In section 3, we will show that $\tau_{c}$ exhibits large variations in the wavenumber-frequency domain, ranging from 3 to $24 \mathrm{~h}$. However, in order to obtain simple wave solutions, $\tau_{c}$ will be assumed constant in the remainder of this section. Values of 2 and $12 \mathrm{~h}$ will be used to test the sensitivity of the wave solutions to convective adjustment.

Multiple studies have shown that anomalous longwave radiative heating $R^{\prime}$ plays a central role in low-frequency convectively coupled waves in the tropics (Andersen and Kuang 2012; Kim et al. 2015; Wolding et al. 2016; Shi et al. 2018). Following previous studies, we estimate the anomalous radiative heating as a linear function of the anomalous precipitation:

$$
R^{\prime}=r L_{v} P^{\prime}
$$

where $L_{v}=2.5 \times 10^{6} \mathrm{~J} \mathrm{~kg}^{-1}$ is the latent heat of vaporization and $r$ is referred to as the cloud-radiative 
TABLE 2. Description of the meaning of the nondimensional numbers described in section 2 and what their large and small limits physically describe. The Rossby number (Ro) is included for reference. For the Froude number, gravity waves are the fastest waves that can be obtained from the system of equations shown in Eq. (6), and thus Fr cannot be larger than unity.

\begin{tabular}{|c|c|c|c|c|c|}
\hline Number & Scale name & Meaning & Small limit $(\ll 1)$ & Near unity $(\sim 1)$ & Large limit $(\gg 1)$ \\
\hline Ro & Rossby number & $\begin{array}{l}\text { Ratio of wind acceleration } \\
\text { to Coriolis force }\end{array}$ & $\begin{array}{l}\text { Geostrophic balance } \\
\text { and Rossby waves }\end{array}$ & $\begin{array}{l}\text { Gradient wind balance } \\
\text { and mixed Rossby- } \\
\text { gravity waves }\end{array}$ & $\begin{array}{l}\text { Ageostrophic regime } \\
\text { and gravity waves }\end{array}$ \\
\hline $\mathrm{Fr}^{2}$ & $\begin{array}{l}\text { Froude number } \\
\text { squared }\end{array}$ & $\begin{array}{l}\text { Square of ratio of wave } \\
\text { time scale to gravity } \\
\text { wave time scale }\end{array}$ & WTG balance & Dry gravity waves & - \\
\hline$N_{c}$ & $\begin{array}{l}\text { Convective relaxation } \\
\text { number }\end{array}$ & $\begin{array}{l}\text { Ratio of } \tau_{c} \text { to wave time } \\
\text { scale }\end{array}$ & $\begin{array}{l}\text { Moisture tendency is } \\
\text { negligible }\end{array}$ & Moisture tendency is large & Rainfall is negligible \\
\hline$N_{\text {mode }}$ & Mode number & $\begin{array}{l}\text { Ratio of enthalpy } C_{p} T \text { to } \\
\text { latent energy } L_{v} q\end{array}$ & Moisture modes & $\begin{array}{l}\text { Mixed moisture-gravity } \\
\text { waves }\end{array}$ & Gravity waves \\
\hline
\end{tabular}

feedback parameter (Fuchs and Raymond 2002; Peters and Bretherton 2005) or the greenhouse enhancement factor (Kim et al. 2015). This parameter is nondimensional and studies have estimated it to have a value between 0.1 and 0.2 .

With the above definitions considered, the momentum, thermodynamic and moisture equations for an equatorially trapped, $v=0$ convectively coupled wave take the following form:

$$
\begin{aligned}
\frac{\partial u^{\prime}}{\partial t} & =-\frac{\partial \phi^{\prime}}{\partial x}, \\
\beta y u^{\prime} & =-\frac{\partial \phi^{\prime}}{\partial y}, \\
\frac{\overline{M_{s}}}{c^{2}} \frac{\partial \phi^{\prime}}{\partial t} & =-\bar{M}_{s} \frac{\partial u^{\prime}}{\partial x}-L_{v} P^{\prime}-R^{\prime}, \\
L_{v} \frac{\partial\left\langle q^{\prime}\right\rangle}{\partial t} & =-\bar{M}_{q} \frac{\partial u^{\prime}}{\partial x}-\delta \bar{q}_{u} u^{\prime}-L_{v} P^{\prime},
\end{aligned}
$$

where $u^{\prime}$ is the zonal wind, $\overline{M_{s}}=-\left\langle\Omega \partial_{p} \bar{s}\right\rangle$ is the climatological-mean gross dry stability, where $\Omega$ is the vertical structure of a first baroclinic mode in vertical motion. The negative sign is used in order to make $\overline{M_{s}}$ a positive quantity. $\overline{M_{q}}=\left\langle\Omega \partial_{p} \bar{q}\right\rangle$ is the mean gross moisture stratification, $\bar{s}=C_{p} \bar{T}+\bar{\Phi}$ is the mean dry static energy; $c$ is the phase speed of a first baroclinic free gravity wave $\left(c=\sqrt{R_{d} \overline{M_{s}} / C_{p}\langle a\rangle}=50 \mathrm{~m} \mathrm{~s}^{-1}\right)$; and $\delta \bar{q}_{u}$ is the net moistening from the sum of all the processes associated with the zonal wind anomalies (Sobel and Maloney 2013; Adames and Kim 2016). These include processes such as wind-induced surface heat exchange (WISHE) (Emanuel 1987; Neelin et al. 1987; Fuchs and Raymond 2017) and modulation by high-frequency eddy activity (Maloney 2009; Andersen and Kuang 2012). While this moistening process does not play a role in the scaling described in the following subsection, it is included to facilitate comparison to previous studies that analyzed moisture modes (Fuchs and Raymond 2005; Sobel and Maloney 2013; Adames and Kim 2016; Fuchs and Raymond 2017).

We are particularly interested in how variations in moist enthalpy affect convectively coupled tropical motion systems. Moist enthalpy can be thought of as similar to moist static energy but without the contribution from the potential energy. A version of the moist enthalpy equation that will be relevant for the following sections is written as

$$
\frac{\partial h^{\prime}}{\partial t}=\tilde{M} \bar{M}_{s} \frac{\partial u^{\prime}}{\partial x}-\delta \bar{q}_{u} u^{\prime}+R^{\prime},
$$

where $h^{\prime}=L_{v}\left\langle q^{\prime}\right\rangle-\overline{M_{s}} c^{-2} \phi^{\prime}$ is, approximately, the anomalous column-integrated moist enthalpy (Emanuel 1994). The temperature anomaly is related to $\phi^{\prime}$ through hydrostatic balance so that $h^{\prime}$ can be thought of having a moist contribution $L_{v}\left\langle q^{\prime}\right\rangle$ and a thermal component $-\overline{M_{s}} c^{-2} \phi^{\prime}$. The first term on rhs in Eq. (7) corresponds to vertical MSE advection, where $\tilde{M}=\left(\overline{M_{s}}-\overline{M_{q}}\right) / \overline{M_{s}}$ is the normalized vertical gross moist stability (NGMS) (Neelin and Held 1987; Yu et al. 1998; Raymond et al. 2009). The other rhs terms in Eq. (7) have been previously defined.

\section{b. Scale analysis}

Important insight into the dynamics of moist equatorial waves can be obtained by considering a scale analysis for motions that exhibit no meridional wind variation $(v=0)$. While this analysis is heavily idealized, appendix B shows that the scaling shown here is the same for most waves in which $v \neq 0$. The main scaling parameters we obtain from this analysis are summarized in Table 2 . The scaling presented in this section differs from previous studies (Charney 1963; Yano and Bonazzola 2009) in that the time scale of motion is determined by wave propagation (i.e., a wave time scale) rather than by advection by the mean flow 
(i.e., an advective time scale). Since we are dealing with equatorially trapped motions, the zonal and meridional length scales are assumed to be different.

We will begin our analysis by assuming that the characteristic scales for zonal and meridional distance, velocity, and time can be represented by

$$
x \sim L_{x} \hat{x}, \quad y \sim L_{y} \hat{y}, \quad u^{\prime} \sim U \hat{u}, \quad t \sim \tau_{\omega} \hat{t},
$$

where $L_{x}$ is the zonal length scale, $L_{y}$ is the meridional length scale, $U$ is the zonal velocity scale, and $\tau_{\omega}$ is the wave's temporal scale. All variables with circumflexes (e.g., $\hat{u}$ ) correspond to nondimensional fields. Scaling the zonal momentum equation [Eq. (6a)] yields a simple relationship for the magnitude of the geopotential:

$$
\phi^{\prime} \sim U c_{p} \hat{\phi},
$$

where $c_{p}=L_{x} / \tau_{\omega}$ is the phase speed of a wave.

We will now perform a scale analysis on the moisture conservation equation [Eq. (6d)]. For this analysis, we define a moisture scale as $\left\langle q^{\prime}\right\rangle \sim[q] \hat{q}$. The scaled moisture equation takes the following form

$$
\frac{L_{v}[q]}{\tau_{c}}\left(N_{c} \frac{\partial \hat{q}}{\partial \hat{t}}+\hat{q}\right) \sim \frac{\overline{M_{q}} U}{L_{x}} \frac{\partial \hat{u}}{\partial \hat{x}}-U \delta \bar{q}_{u} \hat{u},
$$

where we define a nondimensional number $N_{c}$ as

$$
N_{c} \equiv \frac{\tau_{c}}{\tau_{\omega}}
$$

This number describes the magnitude of the precipitation tendency relative to the precipitation anomalies. In Eq. (9) $N_{c}$ indicates that the moisture tendency is more important the larger $\tau_{c}$ is relative to the time scale of the moist wave. Given that $\tau_{c}$ is on the order of a day or less, $N_{c} \ll 1$ for most observed waves (see also Fig. 3b). Observations indicate that in precipitating regions vertical moisture advection is much larger than horizontal moisture advection or surface latent heat fluxes (Benedict and Randall 2007; Adames and Wallace 2015). It follows that the leading balance in the moisture equation is between vertical moisture advection and precipitation

$$
\frac{L_{v}[q]}{\tau_{c}} \hat{q} \sim-\frac{\overline{M_{q}} U}{L_{x}} \frac{\partial \hat{u}}{\partial \hat{x}}
$$

From Eq. (11) we can obtain a value for $[q]$ :

$$
[q] \sim \frac{N_{c} \overline{M_{q}} U}{L_{v} c_{p}},
$$

which indicates that the relative magnitude of columnintegrated moisture anomalies with respect to the geopotential anomalies are larger if $N_{c}$ is larger or if $c_{p}$ is smaller. With Eq. (12), the scaled moisture equation simplifies to

$$
N_{c} \frac{\partial \hat{q}}{\partial \hat{t}}+\frac{\partial \hat{u}}{\partial \hat{x}} \sim-\hat{q}-\frac{L_{x}}{\bar{M}_{q}} \delta \bar{q}_{u} \hat{u} .
$$

We will now scale the thermodynamic equation in order to determine when the WTG approximation is appropriate. Using the scaling obtained in Eqs. (8) and (12), we obtain the following scaled thermodynamic equation

$$
\operatorname{Fr}^{2} \frac{\partial \hat{\phi}}{\partial \hat{t}}+\frac{\partial \hat{u}}{\partial \hat{x}} \sim(1-\tilde{M})(1+r) \hat{q},
$$

where we define the wave Froude number $(\mathrm{Fr})$ as the ratio of the phase speed of a convectively coupled wave and the phase speed of dry gravity waves

$$
\operatorname{Fr} \equiv \frac{c_{p}}{c}
$$

It follows from the scaling in Eq. (14) that $\mathrm{Fr}^{2}$ is a scale that describes the adjustment toward WTG balance. In the tropics, WTG balance is achieved when temperature perturbations are damped by gravity waves, a process which has been referred to as "gravity wave adjustment" (Wolding and Maloney 2015; Wolding et al. 2016) or "buoyant equalization" (Bretherton and Smolarkiewicz 1989).

Equation (14) indicates that WTG balance is achieved in waves that are substantially slower than dry gravity waves. More quantitatively, one can show that any phase speed less than $15 \mathrm{~m} \mathrm{~s}^{-1}$ satisfies WTG balance since it will yield $\mathrm{Fr}^{2}<0.1$. The equation also indicates that in a dry atmosphere, $1-\tilde{M}=0$ and thus $c_{p}=c$. In that case, Eqs. (6a)-(6c) consist of a system that describes a dry gravity wave.

Another useful expression of Fr can be obtained by defining the gravity wave adjustment time scale (also known as the WTG adjustment time scale; Ruppert and Hohenegger 2018) as the time it takes gravity waves to travel the length scale of the moist wave

$$
\tau_{g}=\frac{L_{x}}{c} .
$$

Note that this time scale is proportional to $L_{x}$ such that $\tau_{g}$ is longer for larger-scale waves. This proportionality is due to gravity waves having to travel a longer distance to homogenize temperature anomalies in large-scale waves. For synoptic-scale waves $\left(L_{x} \sim 10^{6} \mathrm{~m}\right), \tau_{g} \sim 5.6 \mathrm{~h}$ while for 
planetary-scale waves $\left(L_{x} \sim 10^{7} \mathrm{~m}\right) \tau_{g} \sim 56 \mathrm{~h}$. By defining $\tau_{g}$ we can write Fr as

$$
\mathrm{Fr} \equiv \frac{\tau_{g}}{\tau_{\omega}},
$$

which indicates that WTG is applicable when the square of the time scale of the wave is much longer than the square of the gravity wave adjustment time scale $\tau_{g}^{2} \ll \tau_{\omega}^{2}$.

Finally, we will scale the contribution of temperature and moisture to moist enthalpy [Eq. (7)]. To elucidate the discussion, we will define a nondimensional temperature as $\hat{T}=-\hat{\phi}$. Using this definition along with the scaling parameters described here, we obtain the following expression for moist enthalpy [Eq. (7)]:

$$
\begin{aligned}
& N_{c}(1-\tilde{M})\left[N_{\text {mode }} \frac{\partial \hat{T}}{\partial \hat{t}}+\frac{\partial \hat{q}}{\partial \hat{t}}\right] \sim-\frac{L_{x}}{\bar{M}_{s}} \delta \bar{q}_{u} \hat{u}+\tilde{M} \frac{\partial \hat{u}}{\partial \hat{x}} \\
& \quad+r(1-\tilde{M}) \hat{q},
\end{aligned}
$$

where

$$
N_{\text {mode }} \equiv \frac{\mathrm{Fr}^{2}}{N_{c}} \frac{1}{(1-\tilde{M})}
$$

is the mode number, a measure of the relative magnitude of dry enthalpy $C_{p} T$ with respect to latent energy $L_{v} q$, that is, $\hat{h}=N_{\text {mode }} \hat{T}+\hat{q}$. The nondimensional moist enthalpy equation reveals several important insights. When the atmosphere is dry $\left(\tilde{M} \rightarrow 1, N_{\text {mode }} \rightarrow \infty\right)$, all terms associated with moist processes become zero. The resulting equation is the thermodynamic equation of a dry atmosphere, which yields dry gravity waves. However, even when the atmosphere is saturated $(\tilde{M} \rightarrow 0)$, temperature can still dominate the distribution of moist enthalpy if $N_{\text {mode }} \gg 1$.

We can also express $N_{\text {mode }}$ in terms of three different time scales:

$$
N_{\text {mode }} \equiv \frac{\tau_{g}^{2}}{\tau_{\omega} \tau_{c}} \frac{1}{(1-\tilde{M})},
$$

which indicates that temperature anomalies will dominate $h^{\prime}$ if $\tau_{g}^{2}$ is much longer than the product of $\tau_{c}$ and $\tau_{\omega}$. When this occurs, convectively coupled gravity waves can be expected. On the other hand, when $\tau_{g}^{2}$ is much shorter than the product of $\tau_{c}$ and $\tau_{\omega}$ moisture modes can be expected.

Research on convectively coupled motions in the tropics indicates that $\tilde{M}$ is usually on the order of $10^{-1}$. This value has been observed to be relatively uniform at all spatial and temporal scales (Inoue and Back 2015, 2017; Inoue et al. 2019, manuscript submitted to J. Atmos. Sci.). We have verified that space-time spectral variations in $\tilde{M}$ range from 0.03 to 0.12 (not shown). It follows that $\tilde{M}$ contributes to little to $N_{\text {mode }}$, so that for convectively coupled waves it can be approximately written as

$$
N_{\text {mode }} \simeq \frac{\tau_{g}^{2}}{\tau_{\omega} \tau_{c}}=\frac{c_{p}^{2}}{c^{2} N_{c}} .
$$

This simplified version of $N_{\text {mode }}$ will be examined in further detail in section 3 in order to understand the relative role of temperature and moisture in observed tropical motion systems.

\section{c. Linear wave solutions}

Following Matsuno (1966) and Fuchs and Raymond (2017), we assume an equatorially trapped solution to Eqs. (6a), (6c), and (6d) [e.g., $\left.\phi^{\prime}=\phi_{0}(y) \exp (i k x-i \omega t)\right]$. The following dispersion relationship is obtained:

$\omega^{3} \tau_{c}+i \omega^{2}-c^{2} k^{2} \omega \tau_{c}+c^{2} k A_{K}-i c^{2} k^{2} \tilde{M}_{\mathrm{eff}}=0$,

where $\omega$ is the wave frequency, and $A_{K}=\delta \bar{q}_{u}(1+r) / \overline{M_{s}}$ is the moisture advection parameter of a Kelvin wave (Adames and $\operatorname{Kim} 2016)$, and $\tilde{M}_{\text {eff }}=\tilde{M}(1+r)-r$, is the effective gross moist stability, a value of the GMS that incorporates cloud-radiative feedbacks (Sobel and Maloney 2012).

The dispersion is composed of a growing mode and two damped modes. The solution to Eq. (22) that corresponds to a growing mode is shown in Fig. 2 for different values of $\tau_{c}$ and $\tilde{M}_{\text {eff }}$. For large values of $\tau_{c}$ and $\tilde{M}_{\text {eff }}=0$, the solution exhibits a dispersion curve that is reminiscent of a moisture mode (Adames and Kim 2016; Fuchs and Raymond 2017). When $\tau_{c}$ is small and $\tilde{M}_{\text {eff }}=0.2$, the solution exhibits a dispersion curve with a near-constant slope, reminiscent of a gravity wave. Discussion on the meridional structure of this wave solution is found in appendix E. The two damped modes will not be discussed.

We will further simplify our system by assuming that $\omega \tau_{c} \ll 1$, which is justifiable for waves with time scales longer than 10 days and $\tau_{c}$ on the order of half a day. Figure 2 shows that the solution is accurate for waves of zonal wavenumber 5 or less. With this assumption, the solution of Eq. (22) for the growing mode becomes

$$
\omega \simeq \frac{\tau_{c} k^{2} c^{2}}{2 i}\left[1-\left(1-N_{\text {mode }}^{*}\right)^{1 / 2}\right],
$$

where 

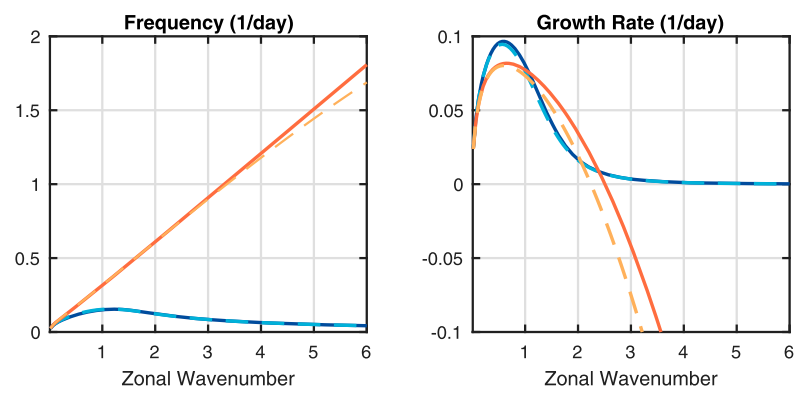

FIG. 2. (left) Frequency and (right) growth rate for the growing solution in Eq. (22) (solid) and the approximate solution in Eq. (23a) (dashed). The solution for $\tilde{M}_{\text {eff }}=0$ and $\tau_{\mathrm{c}}=12 \mathrm{~h}$ is shown in blue. The solution for $\tilde{M}_{\text {eff }}=0.2$ and $\tau_{\mathrm{c}}=2 \mathrm{~h}$ is shown in red. For both lines, $A_{K}=2 \times 10^{-8} \mathrm{~m}^{-1}$.

$$
N_{\text {mode }}^{*}=\frac{\left(\tilde{M}_{\text {eff }}+i A_{K} k^{-1}\right) \tau_{g}^{2}}{\pi^{2} \tau_{c}^{2}}
$$

is a version of $N_{\text {mode }}$ that corresponds to the wave solution sought here, and $\tau_{g}=2 \pi /(c k)$.

In the next subsections, we will show that for large $N_{\text {mode }}^{*}$ our growing mode is consistent with a gravity wave, while for small $N_{\text {mode }}^{*}$ our growing mode is approximately a moisture mode. For values of $N_{\text {mode }}^{*} \sim 1$ the wave exhibits behavior of both a gravity wave and a moisture mode.

\section{1) Convectively coupled GRAVity wave}

A convectively coupled gravity wave solution reminiscent of the wave solution obtained by Neelin and $\mathrm{Yu}$ (1994) arises when considering the case when $\left|N_{\text {mode }}^{*}\right| \gg 1$. We can expand the dispersion relation in Eq. (23a) into a Taylor series and truncate on the second term. For the purpose of illustration, we will examine the case when $A_{K} / k \ll \tilde{M}_{\text {eff }}$. This case is accurate when the amplitude of the combined effect of vertical MSE advection and radiative heating are much larger than the moistening imparted by the zonal winds. The approximate dispersion relation for this case takes the following form:

$$
\begin{aligned}
& \omega_{r} \simeq c k \tilde{M}_{\mathrm{eff}}^{1 / 2}, \\
& \omega_{i} \simeq \frac{c^{2}}{2}\left(\frac{A_{K}}{c \tilde{M}_{\mathrm{eff}}^{1 / 2}}-k^{2} \tau_{c}\right),
\end{aligned}
$$

where $\omega_{r}=\operatorname{Re}(\omega)$ and $\omega_{i}=\operatorname{Im}(\omega)$ are the real and imaginary components of the wave solution. Note that the approximation that leads to Eq. (24) is not valid when $k \rightarrow 0$. The wave solution in Eq. (24) is reminiscent of a convectively coupled Kelvin wave. Unlike observed Kelvin waves, which are most prominent at the synoptic scale (Wheeler and Kiladis 1999), this wave exhibits the largest growth at the planetary scale.

\section{2) $v=0$ MOISTURE MODE}

The moisture mode solution arises when we consider the case when $\left|N_{\text {mode }}^{*}\right| \ll 1$. Following the procedure of section $3 \mathrm{c}(1)$, we obtain the following dispersion:

$$
\begin{aligned}
& \omega_{r} \simeq \frac{A_{K}}{\tau_{c} k}, \\
& \omega_{i} \simeq-\frac{\tilde{M}_{\mathrm{eff}}}{\tau_{c}},
\end{aligned}
$$

which is analogous to the moisture mode solution that previous studies have obtained (Adames and Kim 2016; Fuchs and Raymond 2017). Unlike the moist Kelvin wave, $\tilde{M}_{\text {eff }}$ only plays a role in the maintenance of the moisture mode and $A_{K}$ only plays a role in the propagation.

\section{Insights from observations and reanalysis}

\section{a. Data and methods}

In this section, we will apply the scaling in section $2 b$ to observational and reanalysis data. We make use of the daily mean column-integrated water vapor $\langle q\rangle$ in the ERA-Interim dataset (Dee et al. 2011). The data has a $1.5^{\circ}$ longitude $\times 1.5^{\circ}$ latitude horizontal resolution. Our precipitation measurements come from the Tropical Rainfall Measurement Mission, product 3b42 (Huffman et al. 2007). We have also verified our results with data from the Global Precipitation Climatology Project (Huffman et al. 2001). Finally, daily outgoing longwave radiation (OLR) observations are taken from the dataset compiled by Liebmann and Smith (1996). All fields shown in this study are anomalies obtained by using a 100-day high-pass Lanczos filter (Duchon 1979).

To determine the properties of observed convectively coupled equatorial waves we make use of space-time spectral analysis (Wheeler and Kiladis 1999; Hendon and Wheeler 2008). To extract the signal of convectively coupled equatorial waves, the time series of OLR is divided into 128-day segments that overlap by 64 days. The segments are tapered to zero through the use of a Hanning window. After tapering, complex fast Fourier transforms (FFTs) are computed in longitude and then in time. Finally, the power spectrum is averaged over all segments and over the $10^{\circ} \mathrm{N}-10^{\circ} \mathrm{S}$ latitude belt. The number of degrees of freedom is calculated to be $\sim 136$ [2 (amplitude and phase) $\times 34$ (years) $\times$ 365 (days in a year)/128 (segment length)]. We calculate the signal as $S_{\mathrm{xx}}=\left(P_{\mathrm{xx}}-P_{\mathrm{red}}\right) / P_{\mathrm{xx}}$, where $P_{\mathrm{red}}$ is 
the red spectrum, following the method of (Masunaga 2007), and a value of 0.2 is considered to be statistically significant in this study. The results shown herein are not sensitive to the choice of window as long as it is of 96 days or longer, which is sufficiently long to capture MJO variability in each segment of time.

In the following subsection we will also estimate wavenumber-frequency variations in $N_{\text {mode }}$ [Eq. (21)] Unlike in the previous section, where $\tau_{c}$ was treated as a constant, we will assume that $\tau_{c}$ varies in space and time. Following the methods employed by Yasunaga et al. (2019) and Inoue et al. (2019, manuscript submitted to J. Atmos. Sci.), $\tau_{c}$ can be estimated in the wavenumberfrequency domain as the ratio between the cospectrum $K$ between $P$ and $\langle q\rangle\left[K\left(P^{\prime},\left\langle q^{\prime}\right\rangle\right)\right]$ and the power spectrum of $P\left[P_{\mathrm{xx}}\left(P^{\prime}\right)\right]$

$$
\tau_{c}=\frac{K\left(P^{\prime},\left\langle q^{\prime}\right\rangle\right)}{P_{\mathrm{xx}}\left(P^{\prime}\right)} .
$$

Both $K$ and $P_{\mathrm{xx}}$ are obtained following the method outlined by Hayashi (1979). The values of $K$ and $P_{\mathrm{xx}}$ are obtained for each latitude within the $10^{\circ} \mathrm{N}-10^{\circ} \mathrm{S}$ latitude belt. Their ratio is then averaged over these latitudes to obtain a single wavenumber-frequency distribution as shown in Fig. 3a.

\section{b. Estimation of $N_{\text {mode }}$ from data}

Figure 3a shows the wavenumber-frequency distribution of $\tau_{c}$, estimated through Eq. (26). Even though $\tau_{c}$ exhibits a distribution reminiscent to a red spectrum, it is clear that $\tau_{c}$ is smallest over the Kelvin wave band, with $\tau_{c}$ values of $3 \mathrm{~h}$ or less. It is largest over the band corresponding to large-scale westward-propagating disturbances, where it is on the order of a day. Values corresponding to $\sim 17 \mathrm{~h}$ are observed over the MJO band. It is worth noting that the spectrum of $\tau_{c}$ broadly resembles the cospectrum between precipitation and moist static energy shown in Fig. 2a of Yasunaga et al. (2019), revealing the dominance of moisture at low frequencies. The only significant difference between Fig. 3a and Fig. 2a of Yasunaga et al. (2019) lies in the local maximum in the cospectrum of $P^{\prime}$ and MSE found along the dispersion curves of Kelvin waves, which further indicates the nonnegligible role that dry static energy plays in those waves.

Figure $3 b$ shows the wavenumber-frequency distribution of $N_{\text {mode }}$. The contours approximately follow lines of constant slope, indicating that the phase speed of a wave is its dominant contributor. As a result, $N_{\text {mode }}$ is largest at the highest frequencies and horizontal scales, which corresponds to the fastest waves (i.e., $c_{p}=$ $\omega / k)$. The lowest values of $N_{\text {mode }}$ are located at the lowest frequencies and smaller spatial scales, which corresponds to the slowest waves.

The dispersion curves for inertio-gravity are well embedded in the region where $N_{\text {mode }} \gg 1$, indicating that the thermodynamics of these waves are predominantly driven by thermal fluctuations, as indicated by previous studies (Mapes et al. 2006; Raymond et al. 2007; Raymond and Fuchs 2009). Although not shown, the spectral signature of mixed Rossby-gravity waves is also well within the gravity wave region of the spectrum $\left(N_{\text {mode }} \gg 1\right)$. The Kelvin wave band lies mostly along the gravity wave end of the spectrum, although smaller values of $N_{\text {mode }}$ of roughly 3 are also observed. This indicates that gravity wave dynamics are, on average, dominant in Kelvin waves, although the role of moisture may not be negligible, as posited by Kuang (2008).

Along the MJO band (dashed box in Fig. 3) $N_{\text {mode }}$ exhibits values $\sim 0.1$ near zonal wavenumbers $3-10$ and time scales longer than 50 days. Larger values are observed near zonal wavenumber 1 and a time scale of 20 days. This result indicates that the largest-scale components of the MJO might not be explained as a moisture mode, but may also exhibit gravity wave properties $\left(N_{\text {mode }} \sim 1\right)$. It has been shown by numerous studies that the part of the MJO cycle when the anomalous circulation travels through the Western Hemisphere can be understood as a circumnavigating Kelvin wave (Matthews 2008; Haertel et al. 2015; Powell 2017).

That the wavenumber-frequency distribution of $N_{\text {mode }}$ in Fig. 3b approximately follows lines of constant phase speed indicates that $N_{c}$ contributes little to $N_{\text {mode }}$ [see Eq. (19)]. We can further investigate this by analyzing the wavenumber-frequency distribution of $N_{c}$, shown in Fig. 3c. Indeed, there is less variation in $N_{c}$ than in $N_{\text {mode }}$, although this distribution is not constant. The region corresponding to westward-propagating TDlike disturbances exhibits the largest value of $N_{c}$ of $\sim 0.1$ while spectral regions corresponding to the highest and lowest frequencies exhibit values of $\sim 0.02$. Similar values of $\sim 0.03$ are observed at most other wavenumbers and frequencies. When $N_{c}$ is averaged across all wavenumbers and frequencies, a mean value of $\overline{N_{c}} \sim 0.033$ is obtained.

We can obtain a simplified spectrum of $N_{\text {mode }}$ using Eq. (21) but using $\overline{N_{c}}$. The resulting spectrum is shown in Fig. 3d. It is remarkably similar to that shown in Fig. 3b. Thus, to first order, slowly propagating waves are moisture modes while fast waves are gravity waves.

The results of Fig. 3d indicate that a simple qualitative relationship exists between $N_{\text {mode }}$ and $c_{p}$ 

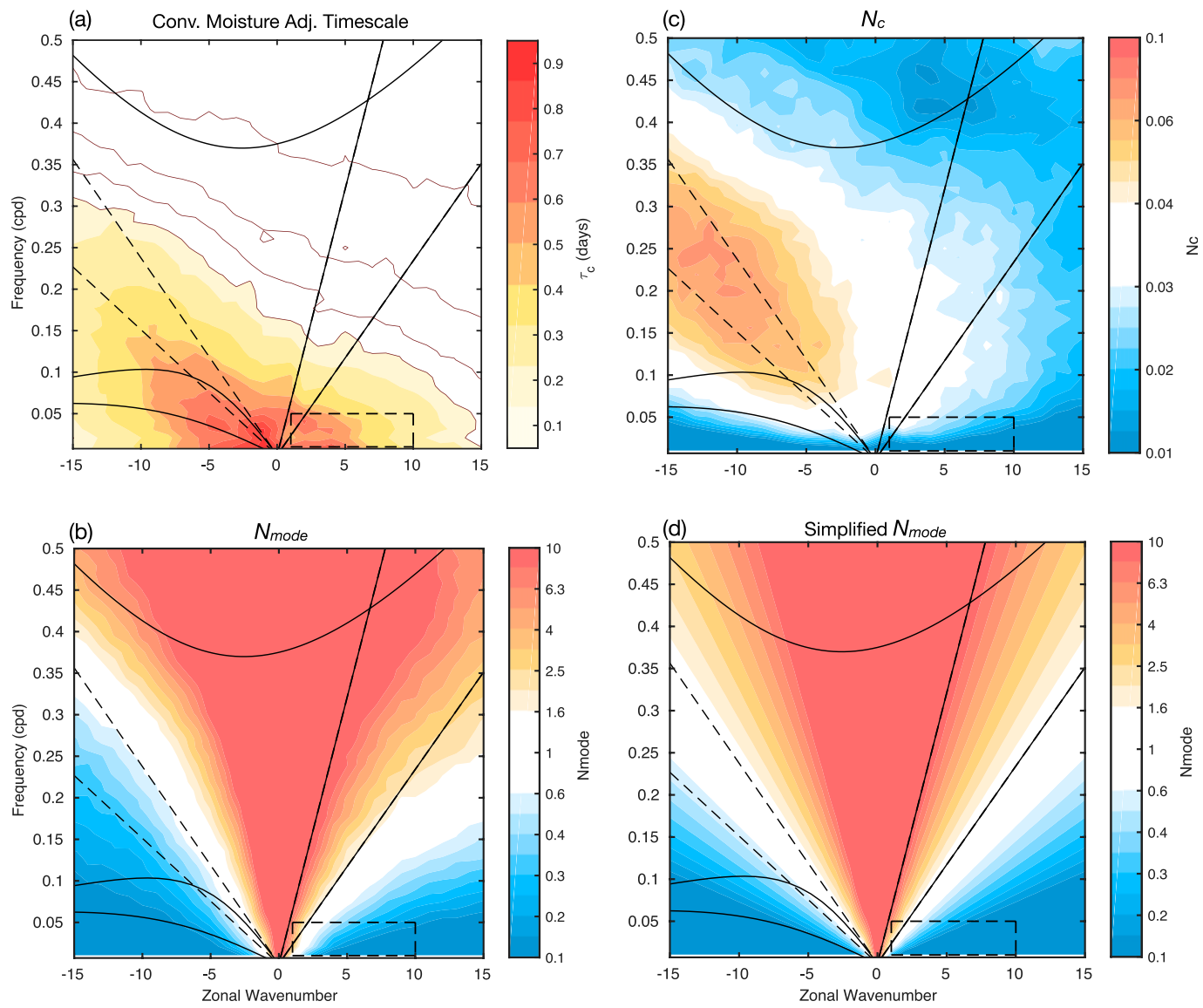

FIG. 3. (a) Convective adjustment time scale $\tau_{c}$ estimated using Eq. (26). (b) $N_{c}$ calculated using the values of $\tau_{c}$ from (a). (c) $N_{\text {mode }}$ estimated using Eq. (19) and utilizing the values of $\tau_{c}$ obtained from (a). (d) As in (c), but using the simplified equation for $N_{\text {mode }}$ [Eq. (27)]. In all panels solid lines correspond to the dispersion curves of Kelvin waves, equatorial Rossby waves, and $n=1$ inertio-gravity waves with equivalent depths of 12 and $90 \mathrm{~m}$. The dashed box encloses eastward-propagating wavenumbers 1-10 and time scales of 20-100 days, which correspond to the traditional MJO band. The dashed lines in westward-propagating zonal wavenumbers correspond to constant phase speeds of -7 and $-11 \mathrm{~m} \mathrm{~s}^{-1}$, which delineate the spectral region where TD-like disturbances are found (Yasunaga and Mapes 2012). The frequency is in units of cycles per day and the zonal wavenumber is expressed as cycles around the circumference of the equator.

$$
N_{\text {mode }} \sim m c_{p}^{2},
$$

where $m=\bar{N}_{c}^{-1} c^{-2}$ is a constant with an approximate value of 0.01 . The approximate phase speed of a wave as a function of $N_{\text {mode }}$ is shown in Fig. 4. When $N_{\text {mode }} \sim 10^{-1}$, which is characteristic of moisture modes, we obtain a mean phase speed of $c_{p} \sim 3 \mathrm{~m} \mathrm{~s}^{-1}$. On the other hand, for $N_{\text {mode }} \sim 10^{1}$, which is characteristic of gravity waves, we obtain $c_{p} \sim 30 \mathrm{~m} \mathrm{~s}^{-1}$.

To synthesize our results, we can use Eq. (27) to modify the wavenumber-frequency spectrum (Fig. 5a) to show it in terms of the simplified $N_{\text {mode }}$. This alternate way of showing the signal strength is shown in Fig. 5b. By showing the spectrum this way, the gravity wave group is located near the top of the figure, while the moisture mode group is located near the bottom.
As discussed previously, Kelvin waves have among the largest values of $N_{\text {mode }}$ in the symmetric spectrum. Westward-propagating TD-type waves exhibit $N_{\text {mode }}$ values of near unity. Equatorial Rossby waves exhibit $N_{\text {mode }}$ values of $\sim 0.2$, although the analysis shown here may not be fully applicable to these waves (see appendix B). The MJO signal shows the most range in its $N_{\text {mode }}$ value. The MJO-related signal at zonal wavenumber 1 is centered near the $N_{\text {mode }}=1$. The higher wavenumber components of the MJO fall closer to the moisture mode limit of the spectrum.

\section{Discussion and conclusions}

The purpose of this study is to analyze the processes that lead to two seemingly distinct groups of convectively 


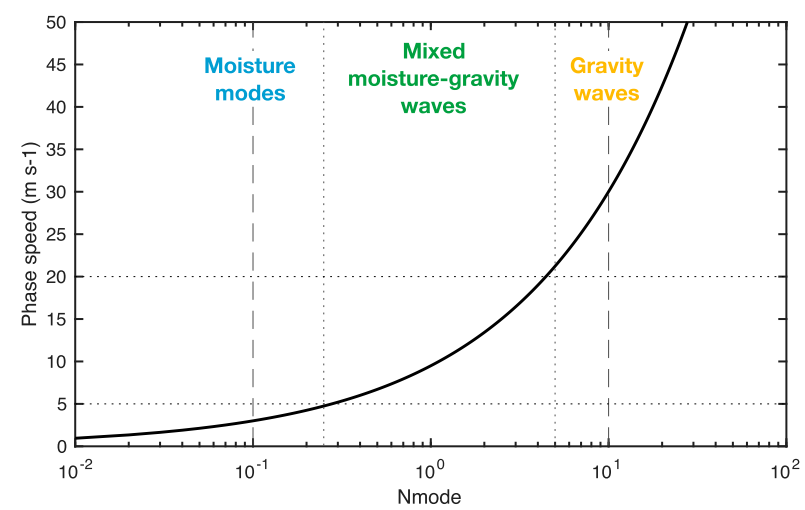

FIG. 4. The approximate phase speed of a wave as a function of $N_{\text {mode }}$ as indicated by Eq. (27). A constant value of $\overline{N_{c}}=0.033$ is used and $c=50 \mathrm{~m} \mathrm{~s}^{-1}$. The vertical dashed lines denote the regions when $N_{\text {mode }}=0.1$ and $N_{\text {mode }}=10$, which delineate the regions where moisture mode and graves are expected, respectively. The vertical dotted lines are for $N_{\text {mode }}=0.25$ and $N_{\text {mode }}=5$, which approximately correspond to the phase speeds of the MJO $\left(5 \mathrm{~m} \mathrm{~s}^{-1}\right)$ and convectively coupled Kelvin waves $\left(20 \mathrm{~m} \mathrm{~s}^{-1}\right)$, respectively.

coupled waves. These are waves in which their thermodynamics are determined by the evolution of moisture (moisture modes), and waves in which their thermodynamics are determined by temperature (gravity waves) (see Fig. 1a). Our study is motivated by the suggestion that these families of waves may not be distinct, but comprise part of a spectrum of observed waves, as indicated by Fig. $1 \mathrm{~b}$ and suggested by previous studies (Roundy 2012a,b; Sobel and Kim 2012; Powell 2017). Our study provides simple scaling arguments that elucidate the physical processes that lead to this spectrum of waves, with the two main groups at the ends of the spectrum.

\section{a. $N_{\text {mode }}$ and the spectrum between moisture modes and gravity waves}

Whether a convectively coupled wave exhibits moisture mode or gravity wave behavior can be understood in terms of a nondimensional mode number $N_{\text {mode }}$ A schematic description of how this ratio affects the distribution of $h^{\prime}$ is shown in Fig. 6. When $\tau_{c}$ is very large relative to $\tau_{g}$ (small $N_{\text {mode }}$ ), precipitation is sufficiently long-lasting that gravity waves can adjust the temperature anomalies to satisfy WTG balance. This results in moisture anomalies being dominant and the behavior of the wave will be that of a moisture mode. When $N_{\text {mode }}$ is large, precipitation removes moisture from the column at a faster rate than gravity waves can relax the temperature anomalies from latent heating toward WTG balance. In such a case, moisture is eliminated quickly and temperature dominates $h^{\prime}$, resulting in convectively coupled gravity waves. For $N_{\text {mode }} \sim 1$ the wave will exhibit behavior of both moisture mode and gravity wave, which we refer to as a mixed moisturegravity (MMG) wave.

Further examination of $N_{\text {mode }}$ reveals that its temporal and spatial variations are predominantly determined by the wave's phase speed. Waves whose phase speed is on the order of $\sim 3 \mathrm{~m} \mathrm{~s}^{-1}$ are likely to be moisture modes while fast waves with phase speeds of $\sim 30 \mathrm{~m} \mathrm{~s}^{-1}$ are likely to be gravity waves. Waves with intermediate phase speeds will exhibit mixed behavior. These results indicate that the moisture budget
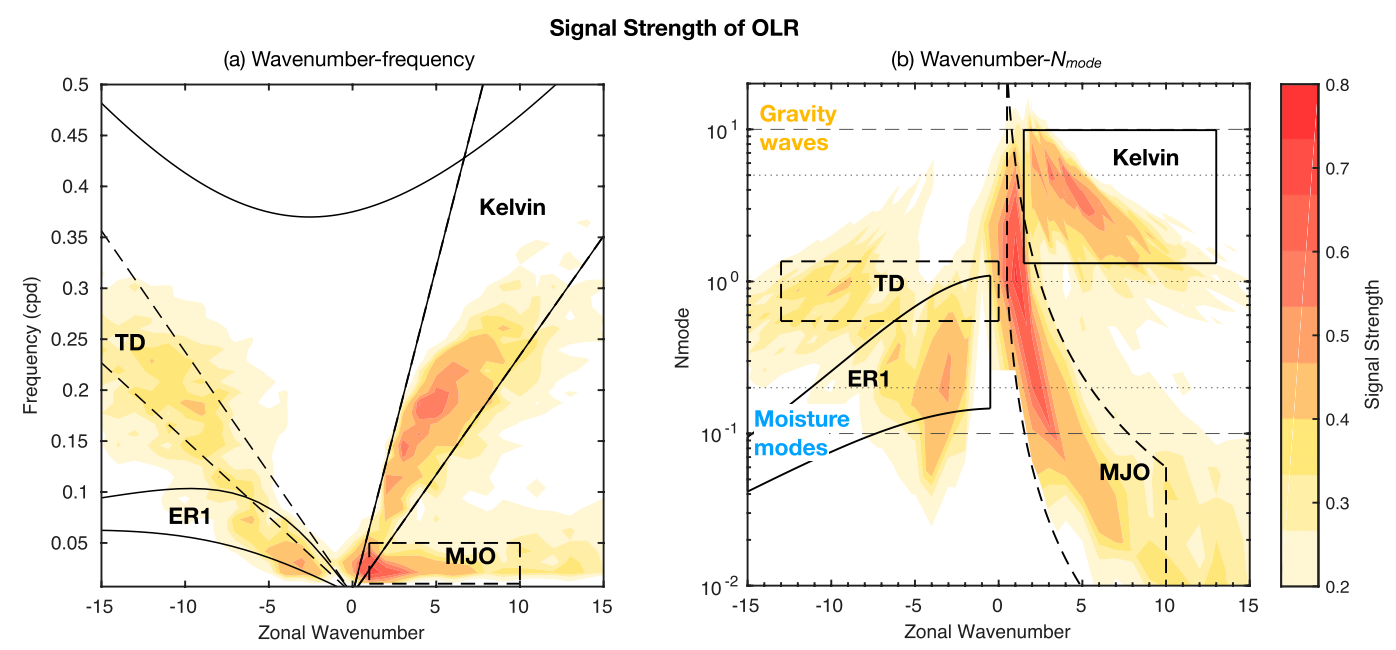

FIG. 5. (a) Signal strength of equatorially symmetric OLR overlaid by the dispersion curves shown in Fig. 3. (b) As in (a), but using the simplified $N_{\text {mode }}$ from Eq. (27) as the y axis. The limits for the moisture mode and gravity wave are shown as dashed horizontal gray lines. Dotted horizontal lines correspond to $N_{\text {mode }}$ values of $0.2,1$, and 5 . 

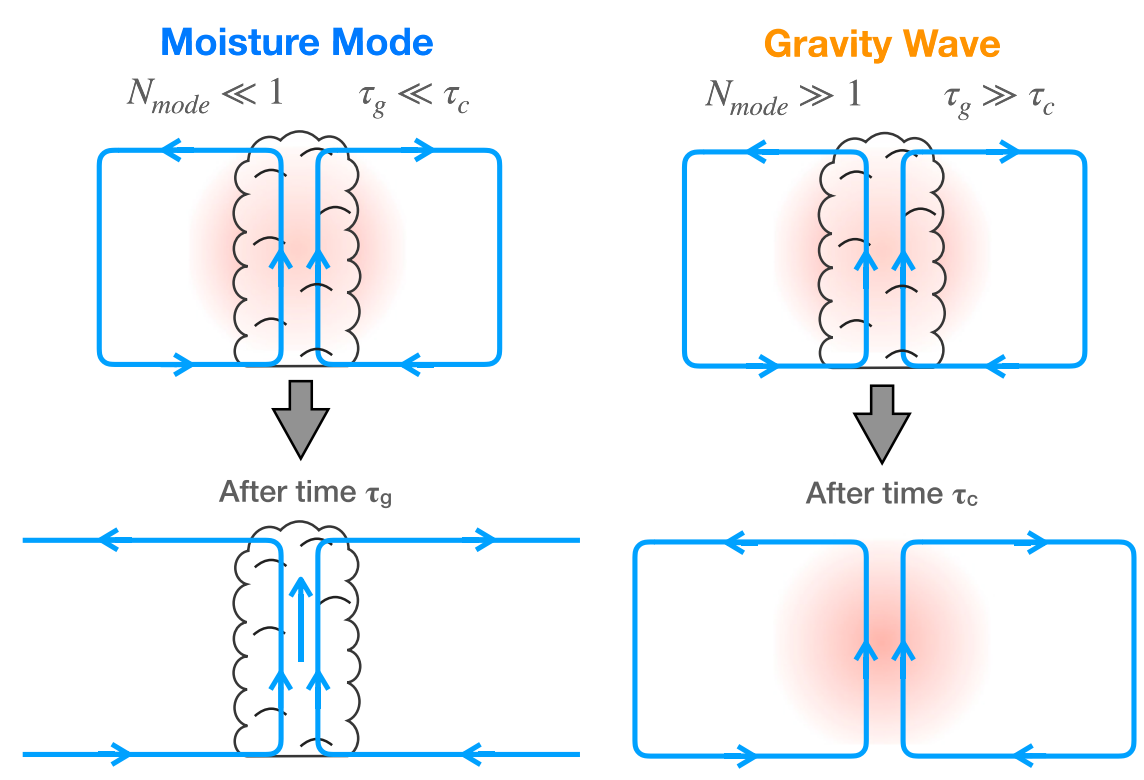

FIG. 6. Schematic describing the mechanism in which a wave could exhibit either gravity wave or moisture mode behavior. (left) In the case when $N_{\text {mode }} \ll 1$ dry gravity waves propagating away from the region of convection homogenize the anomalous temperature (pink shading), resulting in WTG balance. This occurs more quickly than the removal of moisture by convection. As a result, moisture dominates the distribution of $h^{\prime}$ and the dynamics are those of a moisture mode. (right) In the case when $N_{\text {mode }} \gg 1$ convection removes moisture from the column more quickly than what dry gravity waves can adjust the column to WTG balance. As a result, temperature dominates the distribution of $h^{\prime}$ and the resulting dynamics resemble those of a convectively coupled gravity wave.

better describes the processes that lead to the evolution of slow waves while the internal energy budget describes the evolution of fast waves. This finding is consistent with those of previous studies (Raymond et al. 2007; Raymond and Fuchs 2009; Herman et al. 2016; Mapes et al. 2006). It is worth mentioning that the description of waves using $N_{\text {mode }}$ is purely diagnostic. It can only describe the properties of a wave if its phase speed is already known. It cannot be used to explain why different phenomena exhibit different propagation speeds.

\section{b. Analogy to geostrophic adjustment}

The adjustment process that is described by $N_{\text {mode }}$ is analogous to geostrophic adjustment [see section 3.9 in Vallis (2017)]. In geostrophic adjustment, gravity waves induce acceleration in a region of anomalous geopotential that starts at rest. As the gravity waves propagate away from the geopotential anomaly, they become deflected by the Coriolis force, eventually becoming trapped. This trapping results in the temperature anomalies not being fully smoothed out, which results in the wind field adjusting to geostrophic balance. Because it takes a certain amount of time for geostrophic adjustment to occur, not all observed phenomena are in geostrophic balance. Classic scaling arguments for the midlatitudes reveal that whether a phenomenon is able to reach geostrophic balance or not can be understood via the Rossby number (Ro). As described in the previous subsection, $N_{\text {mode }}$ describes an analogous adjustment process. In the same sense that Ro describes the interplay between gravity wave acceleration and the Coriolis force, $N_{\text {mode }}$ describes the interplay between gravity wave adjustment toward WTG balance and convective moisture adjustment.

\section{c. On the spatial and temporal variations of $\tau_{c}$}

A salient feature of the wavenumber-frequency distribution of $\tau_{c}$ in Fig. 3a is that $\tau_{c}$ is larger at the largest scales and lowest frequencies, while exhibiting smaller values at higher frequencies and smaller scales. These are also the spatial and temporal scales in which precipitation and water vapor exhibit the highest coherence (see Fig. 4 in Yasunaga and Mapes 2012). One possible explanation is that precipitation for faster waves is more tightly coupled to fluctuations in CAPE and CIN, as described by Khouider and Majda (2006); Raymond et al. (2007) and Herman et al. (2016), rather than to fluctuations in moisture alone. 
Such a modulation by temperature would increase the amplitude of precipitation without changing the magnitude of the anomalies in specific humidity, thus effectively reducing $\tau_{c}$. Ongoing and future work will seek to answer this question using alternative parameterizations of precipitation that are not just limited to moisture fluctuations (F. Ahmed 2019, personal communication).

\section{d. Relevance to the MJO cycle}

Our results can be used to reinterpret the MJO cycle. Many studies have suggested that a circumnavigating Kelvin wave initiated subsequent MJO events in the Indian Ocean (Knutson and Weickmann 1987; Matthews 2008; Haertel et al. 2015; Powell and Houze 2015). Our results indicate that the circumnavigating signal could be a Kelvin wave that acquires characteristics of a moisture mode as it approaches the Indian Ocean. This transformation may be due to the MJO exhibiting a lower effective GMS value over the warm pool, which results in a smaller $N_{\text {mode }}$. A similar conclusion was obtained by Powell (2017), who found that a parameter $\mu$, which can be thought of as $1-\tilde{M}_{\text {eff }}$, is larger over the warm pool than over the rest of the globe (their Fig. 1). His results indicate that the smallest $\tilde{M}_{\text {eff }}$ values during the MJO cycle occur over the warm pool. $^{1}$

We can investigate the results of Powell (2017) within the context of this study. If we use Eq. (27) along with the phase speed values that Powell (2017) found, we obtain that $N_{\text {mode }} \sim 0.2$ over the warm pool and $N_{\text {mode }}$ $\sim 10$ over the Western Hemisphere. Thus, our results agree with those of Powell (2017) in that the MJO likely exhibits moisture mode behavior in the warm pool, while exhibiting gravity wave behavior over the Western Hemisphere. Thus, it seems like MJO initiation could be a circumnavigating Kelvin wave that obtains moisture mode characteristics as it reaches the warm pool. Such a hypothesis should be examined in the future.

\section{e. Relevance to modeling studies}

Our results may also shed some light as to why some models are able to simulate Kelvin waves but not MJO-like variability, or vice versa. We hypothesize that models that do the former exhibit variability whose GMS is too large, or their convective schemes remove water vapor from the column too quickly (a too-large

\footnotetext{
${ }^{1}$ This lower effective GMS over the warm pool may be specific to the MJO, since the GMS is generally lower over the Atlantic and Pacific ITCZs than near the Maritime Continent (Inoue and Back 2017).
}

$N_{\text {mode }}$ ) (Benedict et al. 2014). Additionally, it may also explain why when entrainment is increased in some models MJO activity is enhanced (Del Genio et al. 2012; Kim et al. 2012; Klingaman and Woolnough 2014; Hannah and Maloney 2014; Zhu and Hendon 2015). When the convective scheme is modified to inhibit convection, $N_{\text {mode }}$ is reduced, which increases the likelihood of simulating moisture mode variability in these models.

\section{f. Caveats and future directions}

While the results presented in this study may provide useful insights of the thermodynamic properties of moist waves, there are nonetheless multiple caveats. While some of these have already been discussed, we summarize them here for convenience:

- A single vertical structure composed of a first baroclinic mode is assumed. Observed waves usually exhibit multiple vertical structures and significant vertical tilts. While this does not necessarily invalidate the scale analysis (section 2b), it does limit the interpretation of the wave solutions (section 2c).

- Precipitation is parameterized only as a function of column-integrated water vapor. Rainfall is also dependent on other parameters such as CAPE and CIN.

- While appendix B shows that the scaling can be extended to waves in which $v \neq 0$, the corresponding wave solutions were not examined in detail.

- The analysis is performed in a linear framework in a precipitating atmosphere. Observed phenomena often exhibit significant nonlinearities and the assumption of a precipitating atmosphere may not always be adequate.

Future work should seek to address these caveats. For example, it is possible to extend the analysis performed here to a framework where no assumptions about the wave's vertical structure are made.

Acknowledgments. ÁFA was supported by the University of Michigan's startup package and by the National Science Foundation Grant AGS-1841559. DK was supported by the National Aeronautics and Space Administration Grant 80NSSC17K0227, the U.S. Department of Energy's Regional and Global Model Analysis program under Grant DE-SC0019495, and Korea Meteorological Administration Research and Development Program under Grant KMI2018-03110. SKC was supported by a National Defense Science and Engineering Graduate Fellowship. KI was supported by an appointment to the NASA Postdoctoral Program at the NASA Goddard Institute for Space Studies, 
administered by Universities Space Research Association under contract with NASA.

\section{APPENDIX A}

\section{Vertical Truncation of the Basic Equations}

In this section we describe the vertical truncation of the field variables shown in the main text. The truncation is that described by Adames and Kim (2016) and Adames and Ming (2018), but it is described here for completeness. We separate the anomalies in vertical velocity $\omega^{\prime}$, horizontal wind $\mathbf{V}^{\prime}=(U, V)$, geopotential $\Phi^{\prime}$, and temperature $T^{\prime}$ into horizontal fields and vertical structure functions

$$
\begin{aligned}
\omega^{\prime}(x, y, p, t) & =D^{\prime}(x, y, t) \Omega(p), \\
\mathbf{V}^{\prime}(x, y, p, t) & =\mathbf{v}^{\prime}(x, y, t) \Lambda(p), \\
\Phi^{\prime}(x, y, p, t) & =\phi^{\prime}(x, y, t) \Lambda(p), \\
T^{\prime}(x, y, p, t) & =\tau^{\prime}(x, y, t) a(p),
\end{aligned}
$$

where $\Omega, \Lambda$, and $a$ are vertical structure functions; $D^{\prime}$ is the anomalous horizontal divergence; and $\mathbf{v}=\left(u^{\prime}, v^{\prime}\right)$, $\phi$, and $\tau$ are the truncated horizontal winds, geopotential, and temperature, respectively. We note that $\Omega$ is the structure function of a first baroclinic mode in vertical motion, a profile descriptive of tropical deep convection; it is described by the following formula:

$$
\Omega(p) \simeq \hat{p}\left(p / p_{s}\right)^{1 / 2} \sin \left[m \ln \left(p_{s} / p\right)\right],
$$

where $\hat{p} \simeq 200 \mathrm{hPa}$ is a reference pressure, $p_{s}=1000 \mathrm{hPa}$ is the surface pressure, and $m=\pi / \ln \left(p_{s} / p_{t}\right)$ is the vertical wavenumber.

The vertical structure function for the winds and geopotential $\Lambda$ is related to $\Omega$ through mass continuity,

$$
\Lambda(p)=-\frac{\partial \Omega(p)}{\partial p},
$$

and $a$ is obtained from hydrostatic balance:

$$
a(p)=\frac{\partial \Lambda(p)}{\partial \ln p} .
$$

For reference, the vertical structures of $\Omega, \Lambda$, and $a$ are shown in Fig. A1.

We can obtain a relationship between the truncated fields $\phi^{\prime}$ and $\tau^{\prime}$ through hydrostatic balance,

$$
\phi^{\prime}=-R_{d} \tau^{\prime},
$$

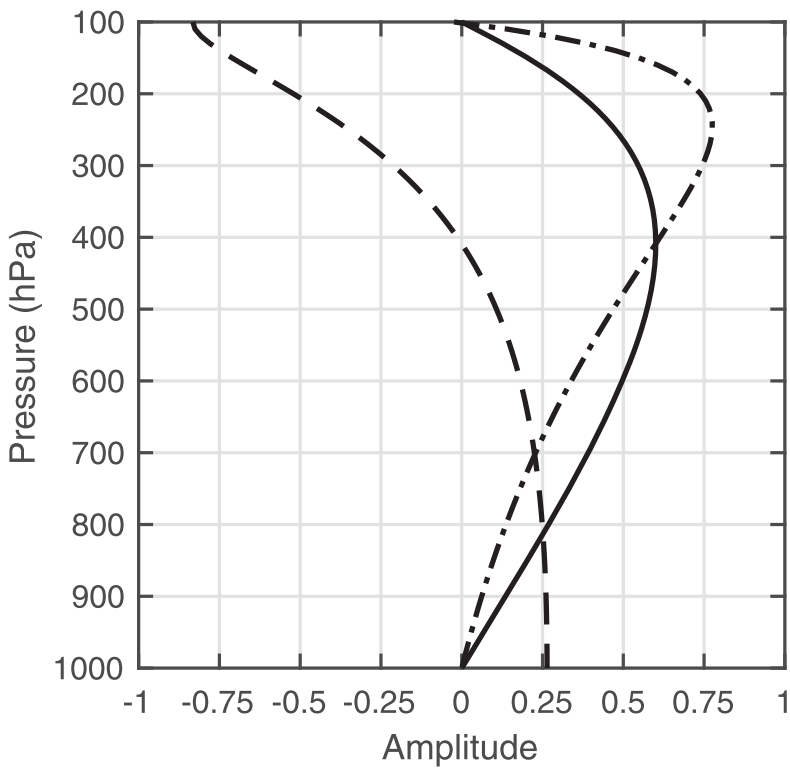

FIG. A1. Basis functions of vertical velocity $\Omega$ (solid), horizontal winds and geopotential $\Lambda$ (dashed), and (c) temperature $a$ (dotdashed). The value of $\Omega$ has been normalized by dividing by $\hat{p}$. See section 2 for further details.

and $D^{\prime}$ is related to the truncated horizontal winds through mass continuity,

$$
D^{\prime}=\nabla \cdot \mathbf{v}^{\prime} .
$$

\section{APPENDIX B}

\section{$\boldsymbol{N}_{\text {mode }}$ Scaling for Motion with $\boldsymbol{v} \neq \mathbf{0}$}

In section $2 \mathrm{~b}$ we presented a scale analysis for moist equatorial waves with $v=0$ and obtained a quantity $N_{\text {mode }}$ which describes the relative roles of moisture and temperature in moist enthalpy. The analysis, while simple, does not represent all motion that occurs on the equatorial belt. In this section we consider the case when $N_{\text {mode }}$ that can be applied to other equatorial phenomena. The analysis follows that of Charney (1963) and Yano and Bonazzola (2009), except the equations are vertically truncated and the time scale $\tau_{\omega}$ is set by wave motions instead of advection. The basic equations take the following form:

$\frac{\partial u^{\prime}}{\partial t}-\beta y v^{\prime}=-\frac{\partial \phi^{\prime}}{\partial x}$,

$\frac{\partial v^{\prime}}{\partial t}+\beta y u^{\prime}=-\frac{\partial \phi^{\prime}}{\partial y}$,

$$
\frac{\overline{M_{s}}}{c^{2}} \frac{\partial \phi^{\prime}}{\partial t}=-\overline{M_{s}} D^{\prime}-L_{v} P^{\prime}-R^{\prime},
$$




$$
L_{v} \frac{\partial\left\langle q^{\prime}\right\rangle}{\partial t}=-\overline{M_{q}} D^{\prime}-\delta \bar{q}_{u} u^{\prime}-\left\langle v^{\prime} \frac{\partial \bar{q}}{\partial y}\right\rangle-L_{v} P^{\prime},
$$

where $D^{\prime}=\partial u^{\prime} / \partial x+\partial v^{\prime} / \partial y$ is the anomalous horizontal divergence and the third rhs is the columnintegrated meridional advection of mean moisture by the anomalous meridional wind, a process shown to be important for MJO propagation (Kim et al. 2014; Adames et al. 2016). Meridional advection is included in order to facilitate comparison with observations and models of the MJO, even though it plays a negligible role in the scaling.

For simplicity, we will assume that $u^{\prime}$ and $v^{\prime}$ follow an aspect ratio scaling $U / L_{x} \sim V / L_{y}$, similar to the one used for the long wave approximation (Gill 1980). Scaling of the zonal and meridional momentum equations, following the parameters discussed in section 2 yields the following scales

$$
U c_{p}\left[\frac{\partial \hat{u}}{\partial \hat{t}}-\frac{1}{\operatorname{Ro}_{e}} \hat{y} \hat{v}\right]=-[\phi] \frac{\partial \hat{\phi}}{\partial \hat{x}},
$$

where we define $\mathrm{Ro}_{e}$ as an equatorial version of the Rossby number

$$
\mathrm{Ro}_{e}=\frac{c_{p}}{\beta L_{y}^{2}}
$$

As in Charney (1963), two different scales for the geopotential can be obtained depending on the relative magnitude of the terms in square brackets in Eq. (B2).

\section{a. Scaling for nonnegligible zonal wind acceleration}

Scaling of the zonal momentum equation reveals that when $\mathrm{Ro}_{e}$ is of magnitude $10^{\circ}$ or greater, then the scaling for geopotential is $[\phi] \sim U c_{p}$. It follows that the scaling for this case identical to that presented in section 2. Given that equatorially trapped waves exhibit a meridional scale of $L_{y} \sim 10^{6} \mathrm{~m}$, and given that $\beta \sim 10^{-11} \mathrm{~m}^{-1} \mathrm{~s}^{-1}$, it follows that this scaling applies to waves that exhibit a phase speed on the order of $10^{1} \mathrm{~m} \mathrm{~s}^{-1}$.

\section{b. Scaling when zonal momentum equation satisfies geostrophic balance}

When $\mathrm{Ro}_{e} \ll 1$, the scaling for the geopotential becomes $[\phi] \sim U c_{p} / \mathrm{Ro}_{e}$. This case corresponds to geostrophic balance in the zonal momentum equation and applies to waves with propagation speeds on the order of $10^{0} \mathrm{~m} \mathrm{~s}^{-1}$. Scaling for this case also follows that described in section 2, except that the scaling for the geopotential is different. In this case, we obtain the following definition for $N_{\text {mode }}$

$$
N_{\text {mode }}=\frac{\operatorname{Fr}^{2}}{N_{c} \operatorname{Ro}_{e}} \frac{1}{(1-\tilde{M})} .
$$

Note that $1 / \mathrm{Ro}_{e}$ increases the magnitude of $N_{\text {mode }}$, so that the temperature anomalies are larger for these waves, consistent with the large geopotential anomalies observed in systems that exhibit geostrophic balance.

\section{APPENDIX C}

\section{$N_{\text {mode }}$ Scaling for the MJO}

In this section we will show that the $N_{\text {mode }}$ scaling discussed in the main text can also be applied to the MJO, even though the MJO exhibits significant meridional flow $(v \neq 0)$. To show this, we invoke Eq. (B2) and perform scale analysis with scaling values that qualitatively correspond to observations of the MJO. Since the MJO is planetary-scale phenomenon, its zonal scale is on the order of $L_{x} \sim 10^{7} \mathrm{~m}$ while equatorial trapping indicates that $L_{y} \sim 10^{6} \mathrm{~m}$. Given that the MJO's phase speed has been estimated to be between 4.7 and $6.6 c_{p} \sim 10^{1} \mathrm{~m} \mathrm{~s}^{-1}$ (Adames and Kim 2016; Powell 2017), we will use a scale for the phase speed of $c_{p} \sim 10^{1} \mathrm{~m} \mathrm{~s}^{-1}$, which yields $\mathrm{Ro}_{e} \sim 10^{0}$. As a result, the two terms in square brackets in Eq. (B2) are of comparable magnitude, which indicates that $\varphi$ scales following Eq. (8). It follows that the resulting definition of $N_{\text {mode }}$ is identical to that shown in the main text. If we used more realistic values of $c_{p}$ and $\beta$ we would obtain values of $1 / \mathrm{Ro}_{e}$ that range from 3 to 4.5 , which still qualitatively satisfies the scaling in Eq. (8).

\section{APPENDIX D}

\section{The Second Baroclinic Mode and the Observed Structure of Convectively Coupled Kelvin Waves}

It is important to note that the convectively coupled gravity wave solution obtained in section $2 c(1)$ exhibits only a first baroclinic structure in vertical motion, temperature and wind. Observed convectively coupled Kelvin waves exhibit more complex structures that include a second baroclinic mode (Wheeler et al. 2000; Straub and Kiladis 2003; Kiladis et al. 2009; Herman et al. 2016). While the linear wave solutions discussed do not explain the vertical structure and instability mechanism of observed Kelvin waves, the scale analysis is still be applicable. If we assume that convectively coupled Kelvin waves exhibit a predominantly second baroclinic structure, 
then $c=27 \mathrm{~m} \mathrm{~s}^{-1}$. This slower phase speed will cause $\tau_{g}$ to be nearly twice as long as the case for the first baroclinic mode, resulting in a larger value of $N_{\text {mode }}$. Waves with phase speeds $\sim 15-20 \mathrm{~m} \mathrm{~s}^{-1}$, as observed in Kelvin waves exhibit $N_{\text {mode }} \sim 10^{1}$. Thus, second baroclinic convectively coupled Kelvin would correspond to the gravity wave group of waves.

\section{APPENDIX E}

\section{Meridional Structure of the $\boldsymbol{v}=0$ Wave Solution}

Using the scale for the geopotential anomaly in Eq. (8), scaling the meridional momentum equation yields the following expression for $L_{y}$ :

$$
L_{y} \sim\left(\frac{c_{p}}{\beta}\right)^{1 / 2},
$$

which resembles the equatorial Rossby radius of deformation, except the free gravity phase speed has been replaced by the phase speed of the wave solution in section $2 \mathrm{c}$.

Finding an equatorial wave solution to the system of equations [Eq. (6)] yields the following meridional variation in the wave:

$$
\hat{\phi}(y)=\phi_{0}^{\prime} \exp \left(\frac{-\beta k y^{2}}{2 \omega}\right) .
$$

Note that because $\omega$ is complex in these equations, Eq. (E2) will have a decaying component and a sinusoidal component. Assuming that $N_{\text {mode, } r}^{*} \gg N_{\text {mode }, i}^{*}$, where the subscripts $r$ and $i$ denote real and imaginary parts, respectively) the meridional structure has the following form:

$$
\hat{\phi}(y)=\phi_{0}^{\prime} \exp \left(\frac{-y^{2}}{2 R_{e}^{2}}\right) \exp \left(\frac{i y^{2} \omega_{i}}{2 R_{e}^{2} \omega_{r}}\right),
$$

where $R_{e}$ is the equatorial Rossby radius of deformation, and $\omega_{r}$ and $\omega_{i}$ are the real and imaginary parts of the dispersion relation. The equatorial radius of deformation is of particular interest, since it is usually defined for dry motions as $R_{e}=\sqrt{c / \beta}$. For this wave solution, however, it takes the form $R_{e}=\sqrt{c_{p} / \beta}$, where $c_{p}$ is the phase speed of the wave solution. For the convectively coupled gravity wave $R_{e}=\sqrt{\tilde{M}_{\mathrm{eff}}^{1 / 2} c / \beta}$ while for the moisture mode solution $R_{e}=\sqrt{A_{K} /\left(\tau_{c} k^{2} \beta\right)}$. Both the moisture mode and the convectively coupled gravity wave are more equatorially trapped than the free wave counterparts.

\section{REFERENCES}

Adames, Á. F., 2017: Precipitation budget of the Madden-Julian oscillation. J. Atmos. Sci., 74, 1799-1817, https://doi.org/ 10.1175/JAS-D-16-0242.1.

— , and J. M. Wallace, 2015: Three-dimensional structure and evolution of the moisture field in the MJO. J. Atmos. Sci., 72, 3733-3754, https://doi.org/10.1175/JAS-D-15-0003.1.

_ , and D. Kim, 2016: The MJO as a dispersive, convectively coupled moisture wave: Theory and observations. J. Atmos. Sci., 73, 913-941, https://doi.org/10.1175/JAS-D-15-0170.1.

_- and Y. Ming, 2018: Interactions between water vapor and potential vorticity in synoptic-scale monsoonal disturbances: Moisture vortex instability. J. Atmos. Sci., 75, 2083-2106, https://doi.org/10.1175/JAS-D-17-0310.1.

_ J. M. Wallace, and J. M. Monteiro, 2016: Seasonality of the structure and propagation characteristics of the MJO. J. Atmos. Sci., 73, 3511-3526, https://doi.org/10.1175/JAS-D15-0232.1.

Andersen, J. A., and Z. Kuang, 2012: Moist static energy budget of MJO-like disturbances in the atmosphere of a zonally symmetric aquaplanet. J. Climate, 25, 2782-2804, https://doi.org/ 10.1175/JCLI-D-11-00168.1.

Benedict, J. J., and D. A. Randall, 2007: Observed characteristics of the MJO relative to maximum rainfall. J. Atmos. Sci., 64, 2332-2354, https://doi.org/10.1175/JAS3968.1.

— E. D. Maloney, A. H. Sobel, and D. M. W. Frierson, 2014: Gross moist stability and MJO simulation skill in three fullphysics GCMs. J. Atmos. Sci., 71, 3327-3349, https://doi.org/ 10.1175/JAS-D-13-0240.1.

Betts, A. K., 1986: A new convective adjustment scheme. Part I: Observational and theoretical basis. Quart. J. Roy. Meteor. Soc., 112, 677-691, https://doi.org/10.1002/QJ.49711247307.

_- and M. Miller, 1986: A new convective adjustment scheme. Part II: Single column tests using GATE wave, BOMEX, ATEX and Arctic air-mass data sets. Quart. J. Roy. Meteor. Soc., 112, 693-709, https://doi.org/10.1002/ QJ.49711247308.

Bretherton, C. S., and P. K. Smolarkiewicz, 1989: Gravity waves, compensating subsidence and detrainment around cumulus clouds. J. Atmos. Sci., 46, 740-759, https://doi.org/10.1175/ 1520-0469(1989)046<0740:GWCSAD > 2.0.CO;2.

- M. E. Peters, and L. E. Back, 2004: Relationships between water vapor path and precipitation over the tropical oceans. J. Climate, 17, 1517-1528, https://doi.org/10.1175/15200442(2004)017<1517:RBWVPA>2.0.CO;2.

Chang, C.-P., 1970: Westward propagating cloud patterns in the tropical Pacific as seen from time-composite satellite photographs. J. Atmos. Sci., 27, 133-138, https://doi.org/10.1175/ 1520-0469(1970)027<0133:WPCPIT>2.0.CO;2.

Charney, J. G., 1963: A note on large-scale motions in the tropics. J. Atmos. Sci., 20, 607-609, https://doi.org/10.1175/15200469(1963)020<0607:ANOLSM > 2.0.CO;2.

Dee, D. P., and Coauthors, 2011: The ERA-Interim reanalysis: Configuration and performance of the data assimilation system. Quart. J. Roy. Meteor. Soc., 137, 553-597, https://doi.org/ 10.1002/qj.828.

Del Genio, A. D., Y. Chen, D. Kim, and M.-S. Yao, 2012: The MJO transition from shallow to deep convection in CloudSat/ CALIPSO data and GISS GCM simulations. J. Climate, $\mathbf{2 5}$, 3755-3770, https://doi.org/10.1175/JCLI-D-11-00384.1.

Duchon, C. E., 1979: Lanczos filtering in one and two dimensions. J. Appl. Meteor., 18, 1016-1022, https://doi.org/10.1175/15200450(1979)018<1016:LFIOAT>2.0.CO;2. 
Emanuel, K. A., 1987: An air-sea interaction model of intraseasonal oscillations in the tropics. J. Atmos. Sci., 44, 2324-2340, https:// doi.org/10.1175/1520-0469(1987)044<2324:AASIMO>2.0.CO;2.

—, 1994: Atmospheric Convection. Oxford University, 580 pp.

Frierson, D. M. W., 2007: The dynamics of idealized convection schemes and their effect on the zonally averaged tropical circulation. J. Atmos. Sci., 64, 1959-1976, https://doi.org/10.1175/ JAS3935.1.

Fuchs, Ž., and D. J. Raymond, 2002: Large-scale modes of a nonrotating atmosphere with water vapor and cloud-radiation feedbacks. J. Atmos. Sci., 59, 1669-1679, https://doi.org/ 10.1175/1520-0469(2002)059<1669:LSMOAN>2.0.CO;2.

$\longrightarrow$, and — 2005: Large-scale modes in a rotating atmosphere with radiative-convective instability and WISHE. J. Atmos. Sci., 62, 4084-4094, https://doi.org/10.1175/JAS3582.1.

— J. Adv. Model. Earth Syst., 9, 1195-1211, https://doi.org/ 10.1002/2017MS000963.

Fuchs-Stone, Ž., D. J. Raymond, and S. Senti, 2019: A simple model of convectively coupled equatorial Rossby waves. J. Adv. Model. Earth Syst., 11, 173-184, https://doi.org/ 10.1029/2018MS001433.

Gill, A. E., 1980: Some simple solutions for heat-induced tropical circulation. Quart. J. Roy. Meteor. Soc., 106, 447-462, https:// doi.org/10.1002/qj.49710644905.

Gonzalez, A. O., and X. Jiang, 2019: Distinct propagation characteristics of intraseasonal variability over the tropical west Pacific. J. Geophys. Res. Atmos., 124, 5332-5351, https://doi.org/ 10.1029/2018JD029884.

Grabowski, W. W., and M. W. Moncrieff, 2004: Moistureconvection feedback in the tropics. Quart. J. Roy. Meteor. Soc., 130, 3081-3104, https://doi.org/10.1256/qj.03.135.

Haertel, P., K. Straub, and A. Budsock, 2015: Transforming circumnavigating Kelvin waves that initiate and dissipate the Madden-Julian oscillation. Quart. J. Roy. Meteor. Soc, 141, 1586-1602, https://doi.org/10.1002/QJ.2461.

Hannah, W. M., and E. D. Maloney, 2014: The moist static energy budget in NCAR CAM5 hindcasts during DYNAMO. J. Adv. Model. Earth Syst., 6, 420-440, https://doi.org/ 10.1002/2013MS000272.

Hayashi, Y., 1979: A generalized method of resolving transient disturbances into standing and traveling waves by spacetime spectral analysis. J. Atmos. Sci., 36, 1017-1029, https:// doi.org/10.1175/1520-0469(1979)036<1017:AGMORT> 2.0.CO;2.

Hendon, H. H., and M. C. Wheeler, 2008: Some space-time spectral analyses of tropical convection and planetaryscale waves. J. Atmos. Sci., 65, 2936-2948, https://doi.org/ 10.1175/2008JAS2675.1.

Herman, M. J., Z. Fuchs, D. J. Raymond, and P. Bechtold, 2016: Convectively coupled Kelvin waves: From linear theory to global models. J. Atmos. Sci., 73, 407-428, https://doi.org/ 10.1175/JAS-D-15-0153.1.

Holloway, C. E., and J. D. Neelin, 2009: Moisture vertical structure, column water vapor, and tropical deep convection. J. Atmos. Sci., 66, 1665-1683, https://doi.org/10.1175/2008JAS2806.1.

Houze, R. A., Jr., 2004: Mesoscale convective systems. Rev. Geophys., 42, RG4003, https://doi.org/10.1029/2004RG000150.

Huffman, G. J., R. F. Adler, M. M. Morrissey, D. T. Bolvin, S. Curtis, R. Joyce, B. McGavock, and J. Susskind, 2001: Global precipitation at one-degree daily resolution from multisatellite observations. J. Hydrometeor., 2, 36-50, https://doi.org/10.1175/ 1525-7541(2001)002<0036:GPAODD>2.0.CO;2.
— - and Coauthors, 2007: The TRMM Multisatellite Precipitation Analysis (TMPA): Quasi-global, multiyear, combined-sensor precipitation estimates at fine scales. J. Hydrometeor., 8, 38-55, https://doi.org/10.1175/JHM560.1.

Inoue, K., and L. E. Back, 2015: Gross moist stability assessment during TOGA COARE: Various interpretations of gross moist stability. J. Atmos. Sci., 72, 4148-4166, https://doi.org/ 10.1175/JAS-D-15-0092.1.

_ satellite-based products in the GMS plane. J. Atmos. Sci., 74, 1819-1837, https://doi.org/10.1175/JAS-D-16-0218.1.

Jiang, X., M. Zhao, E. D. Maloney, and D. E. Waliser, 2016: Convective moisture adjustment time scale as a key factor in regulating model amplitude of the Madden-Julian oscillation. Geophys. Res. Lett., 43, 10 412-10 419, https://doi.org/10.1002/ 2016GL070898.

, A. F. Adames, M. Zhao, D. Waliser, and E. Maloney, 2018: A unified moisture mode framework for seasonality of the Madden-Julian oscillation. J. Climate, 31, 4215-4224, https:// doi.org/10.1175/JCLI-D-17-0671.1.

Khouider, B., 2019: Simple models for moist gravity waves. Models for Tropical Climate Dynamics: Waves, Clouds, and Precipitation, Springer, 75-98, https://doi.org/10.1007/978-3-03017775-1_5.

— for convectively coupled tropical waves. Part I: Linear analysis. J. Atmos. Sci., 63, 1308-1323, https://doi.org/10.1175/ JAS3677.1.

Kiladis, G. N., M. C. Wheeler, P. T. Haertel, K. H. Straub, and P. E. Roundy, 2009: Convectively coupled equatorial waves. Rev. Geophys., 47, RG2003, https://doi.org/10.1029/ 2008RG000266.

Kim, D., A. H. Sobel, A. D. Del Genio, Y. Chen, S. J. Camargo, M.-S. Yao, M. Kelley, and L. Nazarenko, 2012: The tropical subseasonal variability simulated in the NASA GISS general circulation model. J. Climate, 25, 4641-4659, https://doi.org/ 10.1175/JCLI-D-11-00447.1.

, J.-S. Kug, and A. H. Sobel, 2014: Propagating versus nonpropagating Madden-Julian oscillation events. J. Climate, 27, 111-125, https://doi.org/10.1175/JCLI-D-13-00084.1.

—, M.-S. Ahn, I.-S. Kang, and A. D. Del Genio, 2015: Role of longwave cloud-radiation feedback in the simulation of the Madden-Julian oscillation. J. Climate, 28, 6979-6994, https:// doi.org/10.1175/JCLI-D-14-00767.1.

Klingaman, N. P., and S. J. Woolnough, 2014: Using a case-study approach to improve the Madden-Julian oscillation in the Hadley Centre model. Quart. J. Roy. Meteor. Soc., 140, 24912505, https://doi.org/10.1002/qj.2314.

Knutson, T. R., and K. M. Weickmann, 1987: 30-60 day atmospheric oscillations: Composite life cycles of convection and circulation anomalies. Mon. Wea. Rev., 115, 1407-1436, https://doi.org/10.1175/1520-0493(1987)115<1407: DAOCLC $>2.0 . C O ; 2$.

Kuang, Z., 2008: A moisture-stratiform instability for convectively coupled waves. J. Atmos. Sci., 65, 834-854, https://doi.org/ 10.1175/2007JAS2444.1.

Liebmann, B., and C. A. Smith, 1996: Description of a complete (interpolated) outgoing longwave radiation dataset. Bull. Amer. Meteor. Soc., 77, 1275-1277, https://doi.org/10.1175/ 1520-0477-77.6.1274.

Madden, R., and P. Julian, 1971: Detection of a 40-50 day oscillation in the zonal wind in the tropical Pacific. J. Atmos. Sci., 28, 702-708, https://doi.org/10.1175/1520-0469(1971) 028<0702:DOADOI $>2.0 . C O ; 2$. 
— and - 1972: Description of global scale circulation cells in the tropics with a 40-50 day period. J. Atmos. Sci., 29, 1109-1123, https://doi.org/10.1175/1520-0469(1972)029<1109: DOGSCC $>2.0 . \mathrm{CO} ; 2$.

Majda, A. J., B. Khouider, G. N. Kiladis, K. H. Straub, and M. G. Shefter, 2004: A model for convectively coupled tropical waves: Nonlinearity, rotation, and comparison with observations. J. Atmos. Sci., 61, 2188-2205, https://doi.org/10.1175/ 1520-0469(2004)061<2188:AMFCCT>2.0.CO;2.

Maloney, E. D., 2009: The moist static energy budget of a composite tropical intraseasonal oscillation in a climate model. J. Climate, 22, 711-729, https://doi.org/10.1175/2008JCLI2542.1.

Mapes, B. E., 2000: Convective inhibition, subgrid-scale triggering energy, and stratiform instability in a toy tropical wave model. J. Atmos. Sci., 57, 1515-1535, https://doi.org/10.1175/15200469(2000)057<1515:CISSTE > 2.0.CO;2.

$\longrightarrow$, S. Tulich, J. Lin, and P. Zuidema, 2006: The mesoscale convection life cycle: Building block or prototype for large-scale tropical waves? Dyn. Atmos. Oceans, 42, 3-29, https://doi.org/ 10.1016/j.dynatmoce.2006.03.003.

Masunaga, H., 2007: Seasonality and regionality of the Madden-Julian oscillation, Kelvin wave and equatorial Rossby wave. J. Atmos. Sci., 64, 4400-4416, https://doi.org/ 10.1175/2007JAS2179.1.

Matsuno, T., 1966: Quasi-geostrophic motions in the equatorial area. J. Meteor. Soc. Japan, 44, 25-43, https://doi.org/10.2151/ jmsj1965.44.1_25.

Matthews, A. J., 2008: Primary and successive events in the Madden-Julian oscillation. Quart. J. Roy. Meteor. Soc., 134, 439-453, https://doi.org/10.1002/qj.224.

Neelin, J. D., and I. M. Held, 1987: Modeling tropical convergence based on the moist static energy budget. Mon. Wea. Rev., 115, 3-12, https://doi.org/10.1175/1520-0493(1987) 115<0003:MTCBOT>2.0.CO;2.

- , and J.-Y. Yu, 1994: Modes of tropical variability under convective adjustment and the Madden-Julian oscillation. Part I: Analytical theory. J. Atmos. Sci., 51, 1876-1894, https://doi.org/10.1175/1520-0469(1994)051<1876:MOTVUC> 2.0.CO;2.

—_, and N. Zeng, 2000: A quasi-equilibrium tropical circulation model-Formulation. J. Atmos. Sci., 57, 1741-1766, https:// doi.org/10.1175/1520-0469(2000)057<1741:AQETCM>2.0.CO;2.

— I. M. Held, and K. H. Cook, 1987: Evaporation-wind feedback and low-frequency variability in the tropical atmosphere. J. Atmos. Sci., 44, 2341-2348, https://doi.org/10.1175/15200469(1987)044<2341:EWFALF>2.0.CO;2.

Peters, M. E., and C. S. Bretherton, 2005: A simplified model of the Walker circulation with an interactive ocean mixed layer and cloud-radiative feedbacks. J. Climate, 18, 4216-4234, https:// doi.org/10.1175/JCLI3534.1.

Powell, S. W., 2017: Successive MJO propagation in MERRA-2 reanalysis. Geophys. Res. Lett., 44, 5178-5186, https://doi.org/ 10.1002/2017GL073399.

_— and R. A. Houze, 2015: Effect of dry large-scale vertical motions on initial MJO convective onset. J. Geophys. Res. Atmos., 120, 4783-4805, https://doi.org/10.1002/2014JD022961.

Pritchard, M. S., and C. S. Bretherton, 2014: Causal evidence that rotational moisture advection is critical to the superparameterized Madden-Julian oscillation. J. Atmos. Sci., 71, 800-815, https://doi.org/10.1175/JAS-D-13-0119.1.

Raymond, D. J., and Ž. Fuchs, 2007: Convectively coupled gravity and moisture modes in a simple atmospheric model. Tellus, 59, 627-640, https://doi.org/10.1111/j.1600-0870.2007.00268.x.
— , and —-2009: Moisture modes and the Madden-Julian oscillation. J. Climate, 22, 3031-3046, https://doi.org/10.1175/ 2008JCLI2739.1.

- S. L. Sessions, and Ž. Fuchs, 2007: A theory for the spinup of tropical depressions. Quart. J. Roy. Meteor. Soc., 133, 17431754, https://doi.org/10.1002/QJ.125.

,A. H. Sobel, and Ž. Fuchs, 2009: The mechanics of gross moist stability. J. Adv. Model. Earth Syst., 1, 9, https://doi.org/ 10.3894/JAMES.2009.1.9.

Raymond, D., Ž. Fuchs, S. Gjorgjievska, and S. Sessions, 2015: Balanced dynamics and convection in the tropical troposphere. J. Adv. Model. Earth Syst., 7, 1093-1116, https:// doi.org/10.1002/2015MS000467.

Reed, R. J., and E. E. Recker, 1971: Structure and properties of synoptic-scale wave disturbances in the equatorial western Pacific. J. Atmos. Sci., 28, 1117-1133, https://doi.org/10.1175/ 1520-0469(1971)028<1117:SAPOSS >2.0.CO;2.

Roundy, P. E., 2012a: Observed structure of convectively coupled waves as a function of equivalent depth: Kelvin waves and the Madden-Julian oscillation. J. Atmos. Sci., 69, 2097-2106, https://doi.org/10.1175/JAS-D-12-03.1.

_ 2012b: The spectrum of convectively coupled Kelvin waves and the Madden-Julian oscillation in regions of low-level easterly and westerly background flow. J. Atmos. Sci., 69, 2107-2111, https://doi.org/10.1175/JAS-D-12-060.1.

Ruppert, J. H., and C. Hohenegger, 2018: Diurnal circulation adjustment and organized deep convection. J. Climate, $\mathbf{3 1}$, 4899-4916, https://doi.org/10.1175/JCLI-D-17-0693.1.

Rushley, S. S., D. Kim, C. S. Bretherton, and M.-S. Ahn, 2018: Reexamining the nonlinear moisture-precipitation relationship over the tropical oceans. Geophys. Res. Lett., 45, 11331140, https://doi.org/10.1002/2017GL076296.

Rydbeck, A. V., and E. D. Maloney, 2015: On the convective coupling and moisture organization of east Pacific easterly waves. J. Atmos. Sci., 72, 3850-3870, https://doi.org/10.1175/JAS-D-15-0056.1.

Shi, X., D. Kim, Á. F. Adames, and J. Sukhatme, 2018: WISHEmoisture mode in an aquaplanet simulation. J. Adv. Model. Earth Syst., 10, 2393-2407, https://doi.org/10.1029/2018MS001441.

Sobel, A. H., 2002: Water vapor as an active scalar in tropical atmospheric dynamics. Chaos, 12, 451-459, https://doi.org/ 10.1063/1.1480795.

_ in a single column. J. Climate, 13, 4378-4392, https://doi.org/ 10.1175/1520-0442(2000)013<4378:MTPIAS>2.0.CO;2.

— , and D. Kim, 2012: The MJO-Kelvin wave transition. Geophys. Res. Lett., 39, L20808, https://doi.org/10.1029/2012GL053380.

_ work for modeling the Madden-Julian oscillation. J. Atmos. Sci., 69, 1691-1705, https://doi.org/10.1175/JAS-D-11-0118.1. , and _ 2013: Moisture modes and the eastward propagation of the MJO. J. Atmos. Sci., 70, 187-192, https://doi.org/ 10.1175/JAS-D-12-0189.1.

- J. Nilsson, and L. M. Polvani, 2001: The weak temperature gradient approximation and balanced tropical moisture waves. J. Atmos. Sci., 58, 3650-3665, https://doi.org/10.1175/15200469(2001)058<3650:TWTGAA > 2.0.CO;2.

- S. Wang, and D. Kim, 2014: Moist static energy budget of the MJO during DYNAMO. J. Atmos. Sci., 71, 4276-4291, https:// doi.org/10.1175/JAS-D-14-0052.1.

Straub, K. H., and G. N. Kiladis, 2003: The observed structure of convectively coupled Kelvin waves: Comparison with simple models of coupled wave instability. J. Atmos. Sci., 60 , 1655-1668, https://doi.org/10.1175/1520-0469(2003)060<1655: TOSOCC $>2.0 . \mathrm{CO} ; 2$. 
Sugiyama, M., 2009: The moisture mode in the quasi-equilibrium tropical circulation model. Part I: Analysis based on the weak temperature gradient approximation. J. Atmos. Sci., 66, 15071523, https://doi.org/10.1175/2008JAS2690.1.

Takayabu, Y. N., 1994: Large-scale cloud disturbances associated with equatorial waves. J. Meteor. Soc. Japan II, 72, 433-449, https://doi.org/10.2151/JMSJ1965.72.3_433.

Vallis, G. K., 2017: Atmospheric and Oceanic Fluid Dynamics. 2nd ed. Cambridge University Press, 964 pp.

Wallace, J. M., and L. A. Chang, 1972: On the application of satellite data on cloud brightness to the study of tropical wave disturbances. J. Atmos. Sci., 29, 1400-1403, https://doi.org/ 10.1175/1520-0469(1972)029<1400:OTAOSD>2.0.CO;2.

Wheeler, M., and G. N. Kiladis, 1999: Convectively coupled equatorial waves: Analysis of clouds and temperature in the wavenumber-frequency domain. J. Atmos. Sci., 56, 374-399, https://doi.org/10.1175/1520-0469(1999)056<0374: CCEWAO $>2.0 . \mathrm{CO} ; 2$.

- — — , and P. J. Webster, 2000: Large-scale dynamical fields associated with convectively coupled equatorial waves. J. Atmos. Sci., 57, 613-640, https://doi.org/10.1175/15200469(2000)057<0613:LSDFAW>2.0.CO;2.

Wolding, B. O., and E. D. Maloney, 2015: Objective diagnostics and the Madden-Julian oscillation. Part II: Application to moist static energy and moisture budgets. J. Climate, 28, 77867808, https://doi.org/10.1175/JCLI-D-14-00689.1.

, and M. Branson, 2016: Vertically resolved weak temperature gradient analysis of the Madden-Julian oscillation in
SP-CESM. J. Adv. Model. Earth Syst., 8, 1586-1619, https:// doi.org/10.1002/2016MS000724.

Yanai, M., and M. Murakami, 1970a: A further study of tropical wave disturbances by the use of spectrum analysis. J. Meteor. Soc. Japan II, 48, 185-197, https://doi.org/10.2151/JMSJ1965.48.3_185. , and - 1970b: Spectrum analysis of symmetric and antisymmetric equatorial waves. J. Meteor. Soc. Japan II, 48, 331347, https://doi.org/10.2151/JMSJ1965.48.4_331.

Yano, J.-I., and M. Bonazzola, 2009: Scale analysis for large-scale tropical atmospheric dynamics. J. Atmos. Sci., 66, 159-172, https://doi.org/10.1175/2008JAS2687.1.

Yasunaga, K., and B. Mapes, 2012: Differences between more divergent and more rotational types of convectively coupled equatorial waves. Part I: Space-time spectral analyses. J. Atmos. Sci., 69, 3-16, https://doi.org/10.1175/JAS-D-11033.1 .

S. Yokoi, K. Inoue, and B. E. Mapes, 2019: Space-time spectral analysis of the moist static energy budget equation. J. Climate, 32, 501-529, https://doi.org/10.1175/JCLI-D-180334.1.

Yu, J.-Y., C. Chou, and J. D. Neelin, 1998: Estimating the gross moist stability of the tropical atmosphere. J. Atmos. Sci., 55, 1354-1372, https://doi.org/10.1175/1520-0469(1998)055<1354: ETGMSO $>2.0 . \mathrm{CO} ; 2$.

Zhu, H., and H. Hendon, 2015: Role of large scale moisture advection for simulation of the MJO with increased entrainment. Quart. J. Roy. Meteor. Soc., 141, 2127-2136, https://doi.org/ 10.1002/QJ.2510. 